\title{
Article
}

\section{Dynamics of Central Remyelination and Treatment Evolution in a Model of Multiple Sclerosis with Optic Coherence Tomography}

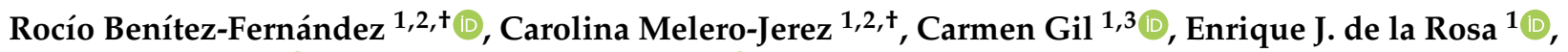 \\ Ana Martínez ${ }^{1,3, *(D)}$ and Fernando de Castro ${ }^{2, *(D)}$ \\ 1 Centro de Investigaciones Biológicas Margarita Salas-CSIC, Ramiro de Maeztu 9, 28040 Madrid, Spain; \\ rocio.benitez@cib.csic.es (R.B.-F.); cmeleroj@gmail.com (C.M.-J.); gil@csic.es (C.G.); \\ ejdelarosa@cib.csic.es (E.J.d.1.R.) \\ 2 Instituto Cajal-CSIC, Avda. Doctor Arce 37, 28002 Madrid, Spain \\ 3 Centro de Investigaciones Biomédicas en Red en Enfermedades Neurodegenerativas (CIBERNED), \\ Instituto de Salud Carlos III, Valderrebollo 5, 28031 Madrid, Spain \\ * Correspondence: ana.martinez@csic.es (A.M.); fdecastro@cajal.csic.es (F.d.C.) \\ + These authors have contributed equally to this work.
}

Citation: Benítez-Fernández, R.; Melero-Jerez, C.; Gil, C.; de la Rosa, E.J.; Martínez, A.; de Castro, F. Dynamics of Central Remyelination and Treatment Evolution in a Model of Multiple Sclerosis with Optic Coherence Tomography. Int. J. Mol. Sci. 2021, 22, 2440. https://doi.org/10.3390/ ijms22052440

Academic Editor:

Florencia Cavodeassi

Received: 21 December 2020

Accepted: 24 February 2021

Published: 28 February 2021

Publisher's Note: MDPI stays neutral with regard to jurisdictional claims in published maps and institutional affiliations.

Copyright: (c) 2021 by the authors. Licensee MDPI, Basel, Switzerland. This article is an open access article distributed under the terms and conditions of the Creative Commons Attribution (CC BY) license (https:// creativecommons.org/licenses/by/ $4.0 /)$

\begin{abstract}
The need for remyelinating drugs is essential for healing disabling diseases such as multiple sclerosis (MS). One of the reasons for the lack of this class of therapies is the impossibility to monitor remyelination in vivo, which is of utmost importance to perform effective clinical trials. Here, we show how optical coherence tomography (OCT), a cheap and non-invasive technique commonly used in ophthalmology, may be used to assess remyelination in vivo in MS patients. Our pioneer approach validates OCT as a technique to study remyelination of the optic nerve and reflects what is occurring in non-accessible central nervous system (CNS) structures, like the spinal cord. In this study we used the orally bioavailable small molecule VP3.15, confirming its therapeutical potential as a neuroprotective, anti-inflammatory, and probably remyelinating drug for MS. Altogether, our results confirm the usefulness of OCT to monitor the efficacy of remyelinating therapies in vivo and underscore the relevance of VP3.15 as a potential disease modifying drug for MS therapy.
\end{abstract}

Keywords: optic coherence tomography; multiple sclerosis; EAE; optic nerve; demyelinating diseases; remyelinating drugs

\section{Introduction}

Multiple sclerosis (MS) is the most common primary demyelinating disease and neurological condition affecting young adults, with about 2.5 million people currently diagnosed around the world [1]. It is characterized by glial cell pathology (especially oligodendrocytes and their precursors), demyelination, inflammatory processes, and axonal damage in the central nervous system (CNS) [2]. In addition to glial cell pathology, the destruction of CNS myelin is accompanied by the activation of macrophages and microglia, cells present in MS lesions that behave either as proinflammatory or anti-inflammatory agents depending on the stage of the lesion [3-6].

An unmet challenge in demyelinating diseases like MS is reestablishing the lost myelin, thus reducing the neurological dysfunction. A proper approach should include three steps: (i) the modulation of the inflammatory response; (ii) the protection of oligodendrocytes; and (iii) the promotion of effective remyelination. Current available treatments are exclusively immunomodulatory, focused on the reduction of inflammation, which ameliorates the evolution of the non-progressive forms of the disease but does not cure them [7]. During the last decade, many studies have investigated myelin regenerating mechanisms. To date, only clemastine fumarate, an old-fashioned antihistaminic drug, has shown relative efficiency on randomized controlled clinical trials as a remyelinating drug [8,9]. Many other targets have been explored with this aim, such as the pathways of Notch and Wnt signaling [10], 
glutamatergic receptors [11], nuclear receptors such as RXRy, PPARy, and VDR [12-14], and components of the extracellular matrix $[15,16]$. Furthermore, different growth factors and chemotropic molecules, like FGF-2 and Anosmin-1, secreted semaphorins and others, have been suggested to cause spontaneous remyelination in human MS $[17,18]$. However, the efficacy of remyelinating therapies is difficult to assess in vivo due to the technical limitations in exploring the CNS, not only in clinical trials but also in preclinical studies where MS animal models are used.

Consequently, there is a need for novel tools to real-time measure and quantify the myelin loss and the effective remyelination after a potential regenerative treatment. Over the past few decades, advanced visualization techniques such as 7-Tesla magnetic resonance imaging (MRI), positron emission tomography (PET), or visual evoked potentials have become pivotal in the diagnosis and monitoring of MS. They have allowed the study of its different aspects, such as the perivascular inflammation, the bursting of new CNS lesions, the activation of the immune response, and the inflammation of leptomeninges [19]. However, because clinical MS reflects a combination of inflammation, degeneration, and regeneration, these techniques fail to detect the remyelination process [20]. For this reason, the spectral domain optic coherence tomography (OCT), a new imaging technology, has emerged in the last few years. OCT is a reproducible and non-invasive method for retinal structure visualization in physiopathological conditions, including neuroinflammatory disorders such as neuromyelitis optica (NMO) and optic neuritis (ON), both in animal models [21] and humans [22,23]. In patients, OCT measurements include the macula volume and the area and thickness of the retinal nerve fiber layer (RNFL), which comprises the axons of the retinal ganglion neurons that converge to form the optic nerve [24]. Because retinal alterations have been described as a component of several MS outcomes, OCT use has been extended to MS in clinical practice for diagnostic purposes, although whether the optic nerve reflects the situation in the parenchimatous CNS remains to be addressed [25-31]. Although a correlation has been described between the decrease in RNFL thickness and brain atrophy in MS [32,33], it has yet to be ascertained whether the results in the RNFL clearly compile the histopathology of the CNS, in terms of inflammation, demyelination status, and oligodendrocyte-lineage cell availability and maturity. The finding of an accurate correlation between the myelin alterations in deep CNS structures and peripheral and technically approachable areas such as the retina would improve the research of remyelinating drugs, elucidating their real-time efficiency in a quantitative manner. It should be noted that, in patients, it is easier to visualize the structure of the retina and the optic nerve head taking advantage of imaging techniques, but it is more difficult to establish correlations within deeper parts of the CNS, hence the need for OCT validation in animal models.

The main goal of the present work is to validate OCT as a methodology to accurately monitor neurological symptoms and histopathological hallmarks in a murine model of MS, i.e., experimental autoimmune encephalomyelitis (EAE). The second aim is to confirm the potential remyelination efficacy of a dual phosphodiesterase-7 (PDE7) and glycogen synthase kinase-3 $\beta$ (GSK3 $\beta$ ) inhibitor named VP3.15 [34]. This compound is a small heterocyclic drug-like molecule with safety profile and good pharmacodynamic and pharmacokinetic properties following intraperitoneal administration previously determined in two different in vivo models [34]. This property is assessed here in the EAE model. Furthermore, VP3.15 has been described as an inducer of remyelination in vitro and in vivo in oligodendrocyte precursor cells (OPCs) isolated from non-tumoral biopsies of human adult brain cortex $[35,36]$. This multitarget compound has also shown anti-inflammatory properties in vivo, both in retinal dystrophies [37] and in the EAE model of MS [38]. The data presented supports OCT as a promising and efficacious tool to evaluate the effects of potential remyelinating drugs in unobservable areas of the CNS. Moreover, a clear correlation between OCT data (retina, the papilla of the optic nerve) and immunohistochemical observations (optic nerve and spinal cord) is demonstrated. Finally, our results confirm the compound VP3.15 as a promising drug candidate for MS therapy. 


\section{Results}

\subsection{The PDE7/GSK3 Dual Inhibitor VP3.15 Ameliorates Clinical Course of Experimental} Autoimmune Encephalomyelitis (EAE)

The dual inhibitor VP3.15, as effective as the oral FDA-approved drug fingolimod in EAE model [38] and with remyelating effect in vitro, ex vivo, and in vivo [35], was the pharmacological tool chosen to test our hypothesis on the usefulness of OCT to monitor remyelination. Benefits of the repeated treatment with VP3.15 (see Methods) in EAE mice were evident since the beginning, with the clinical score (CS) decaying faster and to a significantly lower value in the VP3.15-treated EAE mice by day 19 after onset (Figure 1b). For a more quantitative estimation of the healing effect of VP3.15, we fitted the results to an exponential expression [39], and the score fraction (Sf) obtained was significantly better (0.2) than the EAE-vehicle group (0.3), thus the treatment with VP3.15 ameliorated EAE effects by $33 \%$ compared to the vehicle-treated mice (Figure 1c) by the end of the experiment. In addition to that, the estimated recovery rate $(v)$ was higher in the treated animals (EAE-Veh $=0.187$ days $^{-1}$; EAE-VP3.15 $=0.226$ days $^{-1}$ ) and was reflected in the fact that EAE-VP3.15 reached the endpoint Sf of EAE-VEH nearly 10 days before.

a
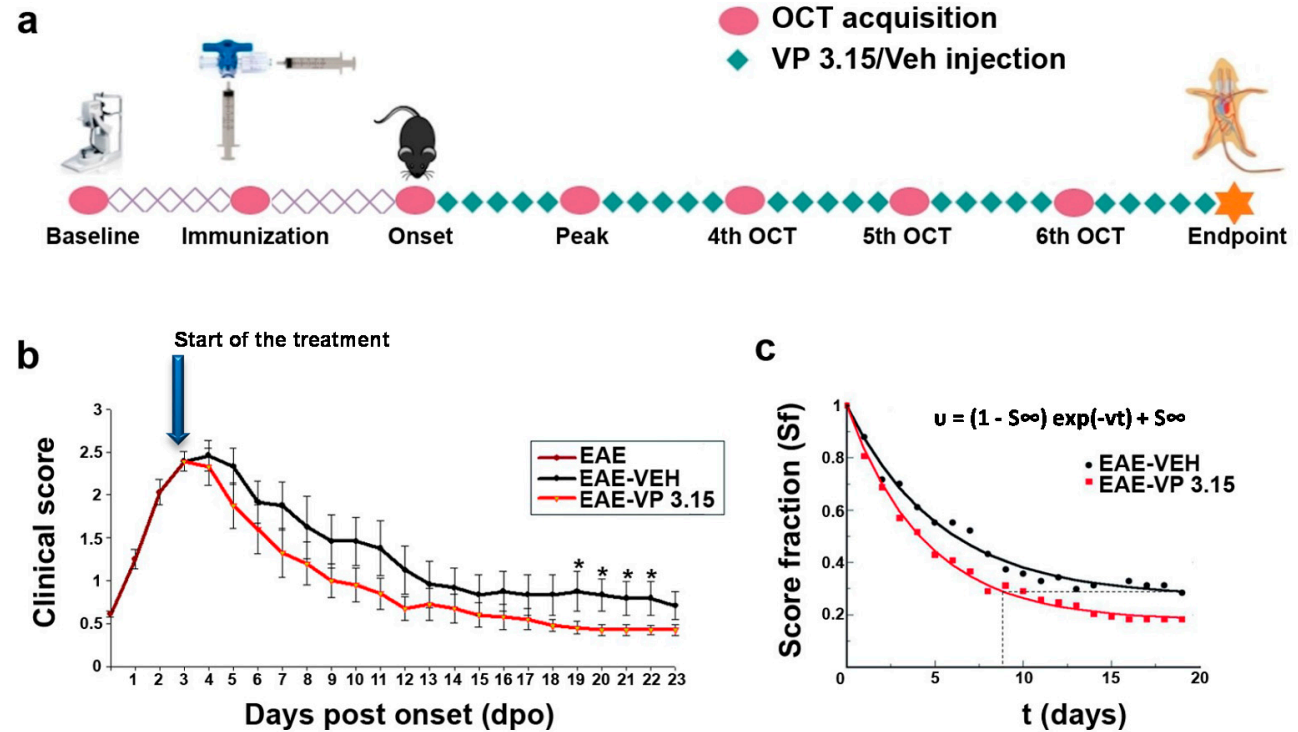

Figure 1. The treatment of experimental autoimmune encephalomyelitis (EAE) mice with the dual inhibitor VP3.15 ameliorates the clinical course from the beginning of the administration; (a): Procedure outline; (b): Time course representation of the clinical performance of EAE mice from the onset of symptoms, showing a lower clinical score in the EAE-VP3.15 compared to EAE-VEH (two-way ANOVA to compare the two treatments: $p<0.05$; results of Student's t-test are represented as: ${ }^{*} p<0.05$ from day 19 to day 22); (c): Exponential expression of the score decay from the beginning of the VP3.15 treatment, where the score (S) at every time point is normalized by the maximal score (Smax). The expression shows that VP3.15 maintains the score in a lower level than vehicle at longer times. Abbreviations: $\mathrm{dpo}=$ days post onset, $\mathrm{Sf}=$ score fraction; $\mathrm{S} \infty=$ score at infinite times. EAE: $n=17$; EAE-VEH: $n=7$; EAE-VP3.15: $n=10$; SHAM: $n=13$.

\subsection{Retinal and Optic Nerve Changes Can Be Monitored Using Optic Coherence Tomography (OCT) in the EAE Model}

Nowadays, retinal layer shrinkage observed by OCT is used in clinics to predict terms of cognitive decline and brain atrophy in MS patients $[33,39,40]$. Our main aim in this work is to check if remyelination, considered as the equilibrium between decreased myelin loss and enhanced new oligodendrocyte precursors cells with subsequent myelin production, can be effectively monitored in real-time using a non-invasive technique such as OCT (see Methods and Figure 2a-d). Besides the predicable stability of retinal thickness in the SHAM group along the entire experiment, we observed that the retina was significantly thinner 
when EAE was induced. As expected, the treatment with VP3.15 showed better dynamics than EAE-VEH, including significant recovery from the sixth OCT onwards (Figure 2e).
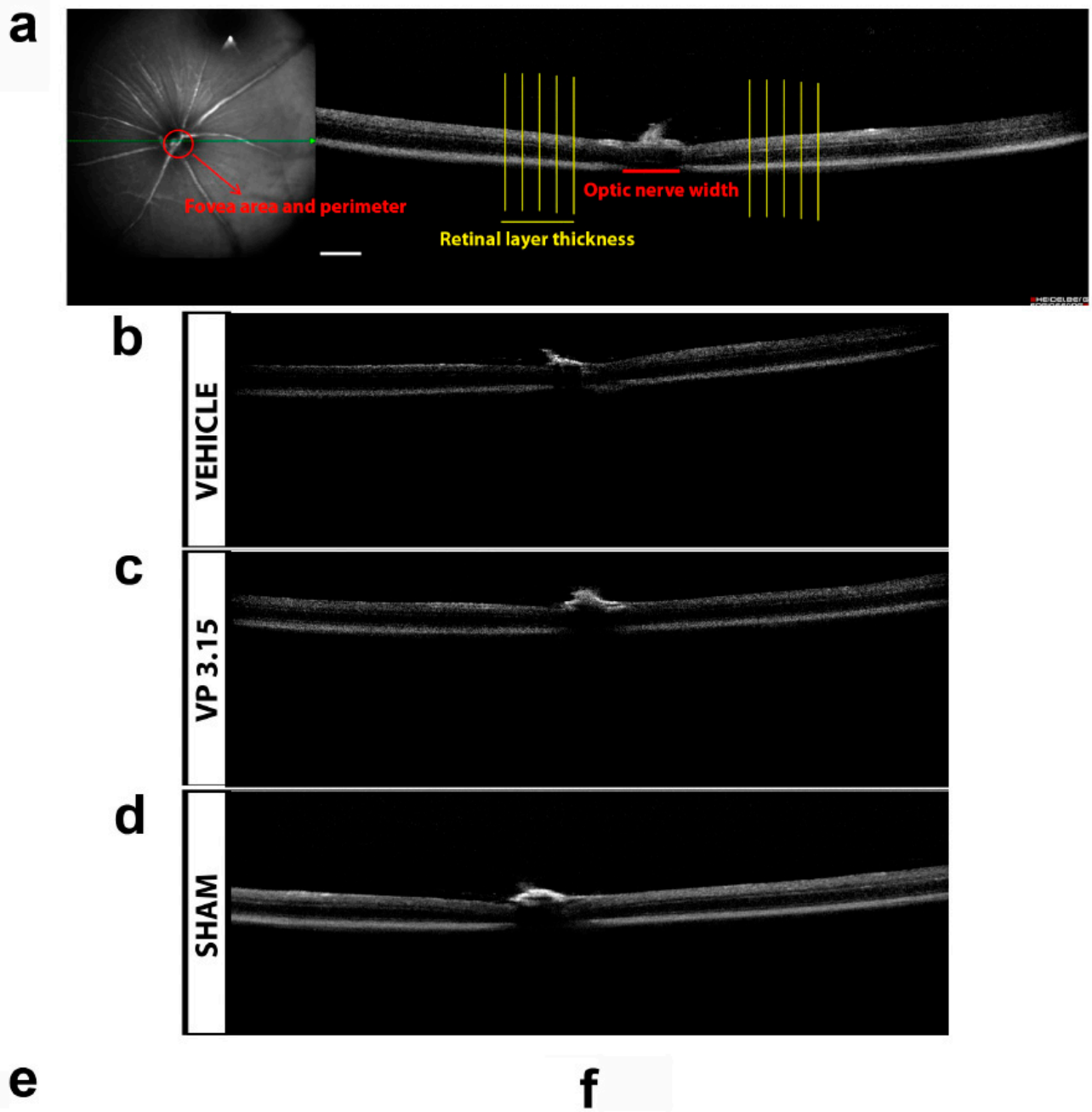

e

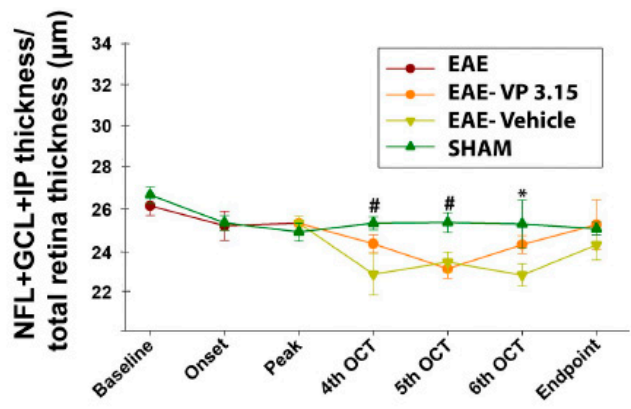

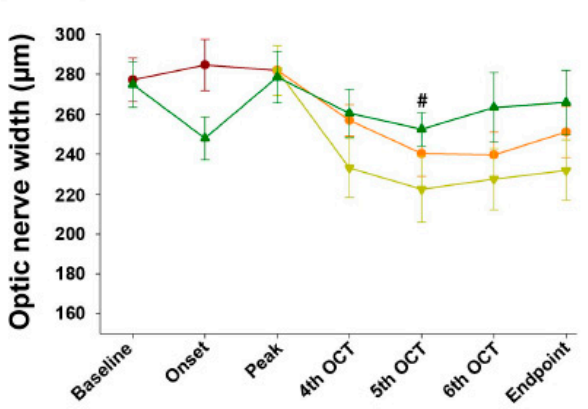

Figure 2. Retina and optic nerve analysis by optical coherence tomography (OCT) of the EAE mice reveals changes associated to the concurrent disease; (a): Schematic representation of the different measurements at the fovea, optic disc, and retina levels; (b-d): Representative images obtained with the OCT; (e): Retinal layer thickness analysis along the experiment; (f): Dynamics of optic nerve width along the experiment. Scale bar represents $200 \mu \mathrm{m}$ in a-d. Abbreviations: GCL = ganglion cell layer; IPL = inner plexiform layer; NFL = nerve fiber layer. Results of Student's $t$-test are represented as: ${ }^{*} p<0.05$ (EAE-VP3.15 vs. EAE-VEH) or $\# p<0.05$ (EAE-VEH vs. SHAM). EAE: $n=17$; EAE-VEH: $n=7$; EAE-VP3.15: $n=10$; SHAM: $n=13$.

These results were more consistent when we measured the optic nerve width: from the fourth OCT to endpoint, the group treated with VP3.15 showed significantly larger OCT measures than non-treated EAE mice (Figure 2f; results of two-way ANOVA Bonferroni 
post-hoc test were $p<0.05)$. Concerning the retina, there was a significant recovery of VP3.15-treated animals after the fifth OCT that was maintained and recovered to the SHAMlike levels at the endpoint. It is also observed that changes in retinal thickness are transient in EAE mice model being almost recovered at the end point. However, optic nerve width, a measure that likely does relate to myelin loss, is greater in the EAE-VEH group than in the VP3.15-treated one, showing the potential remyelinating activity of this new drug. These changes are persistent during the treatment. To further assess the potential of the damaged tissue in the EAE mice, we performed a detailed tissue analysis of the optic nerve (rostral localization, thus closer to the eye) and spinal cord (caudal localization) obtained at the endpoint.

\subsection{The Remyelinating Role and the Effect in the Oligodendrocyte Lineage of VP3.15}

We checked at endpoint the histopathology of two of the most myelinated structures in the CNS: the optic nerve and the spinal cord. In the optic nerve, the treatment with VP3.15 showed an increase higher than $50 \%$ in myelinated $\left(\mathrm{MBP}^{+}\right)$axons when compared with EAE-VEH (Figure $3 a, c, d, f, g)$. In addition, the integrity of the optic nerve axons $\left(\mathrm{NFH}^{+}\right.$) was better preserved in the VP3.15-treated animals compared to the EAE-VEH group (Figure 3b,e,h). This biological effect remarks the neuroprotective profile of VP3.15 and/or the recovery of myelin produced after the treatment.
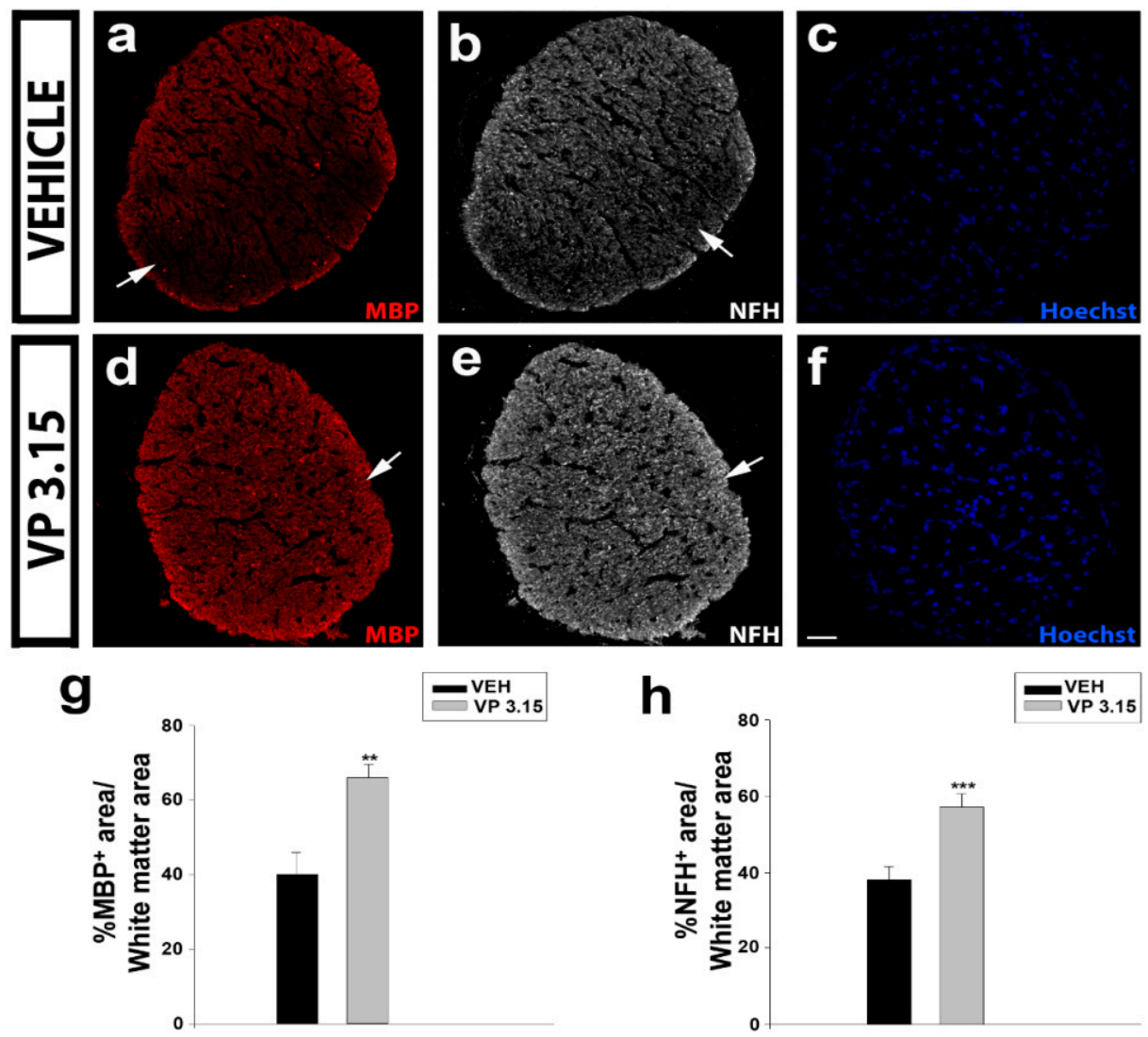

Figure 3. The VP3.15-treated mice preserve the optic nerve from myelin loss and axonal damage; $(\mathbf{a}-\mathbf{f})$ : Detailed views of the optic nerve of vehicle $(\mathbf{a}-\mathbf{c})$ and VP3.15-treated mice $(\mathbf{d}-\mathbf{f})$, labelled for MBP (red), NFH (grey), and nuclei (Hoechst staining; blue); (g,h): Histograms showing a significant increase in the percentage of both $\mathrm{MBP}^{+}(\mathbf{g})$ and $\mathrm{NFH}^{+}(\mathbf{h})$ area in the VP3.15-treated compared to the vehicle-treated mice. Scale bar represents $50 \mu \mathrm{m}$ in a-f. Abbreviations: MBP = myelin basic protein; $\mathrm{NFH}=$ neurofilament heavy. Results of Student's $t$-test are represented as: ${ }^{* *} p<0.01 ;{ }^{* *} p<0.001$. EAE-VEH: $n=7$; EAE-VP3.15: $n=10$. 
Similar results were obtained in the spinal cord: The demyelinated area in the EAEVP3.15 group was significantly lower and showed more $\mathrm{MBP}^{+}$staining than in the EAEVEH (Figure $4 \mathrm{a}-\mathrm{d}, \mathrm{g}-\mathrm{j}$ ), while the axons were also better preserved in the VP3.15-treated group (Figure 4e-f,k). Although it is difficult to compare both structures, our results in the optic nerve seemed slightly more robust than in the spinal cord (percentages in Figure 3g,h vs. in Figure 4i-k), and the remarkable differences in myelination and axonal density could explain them.
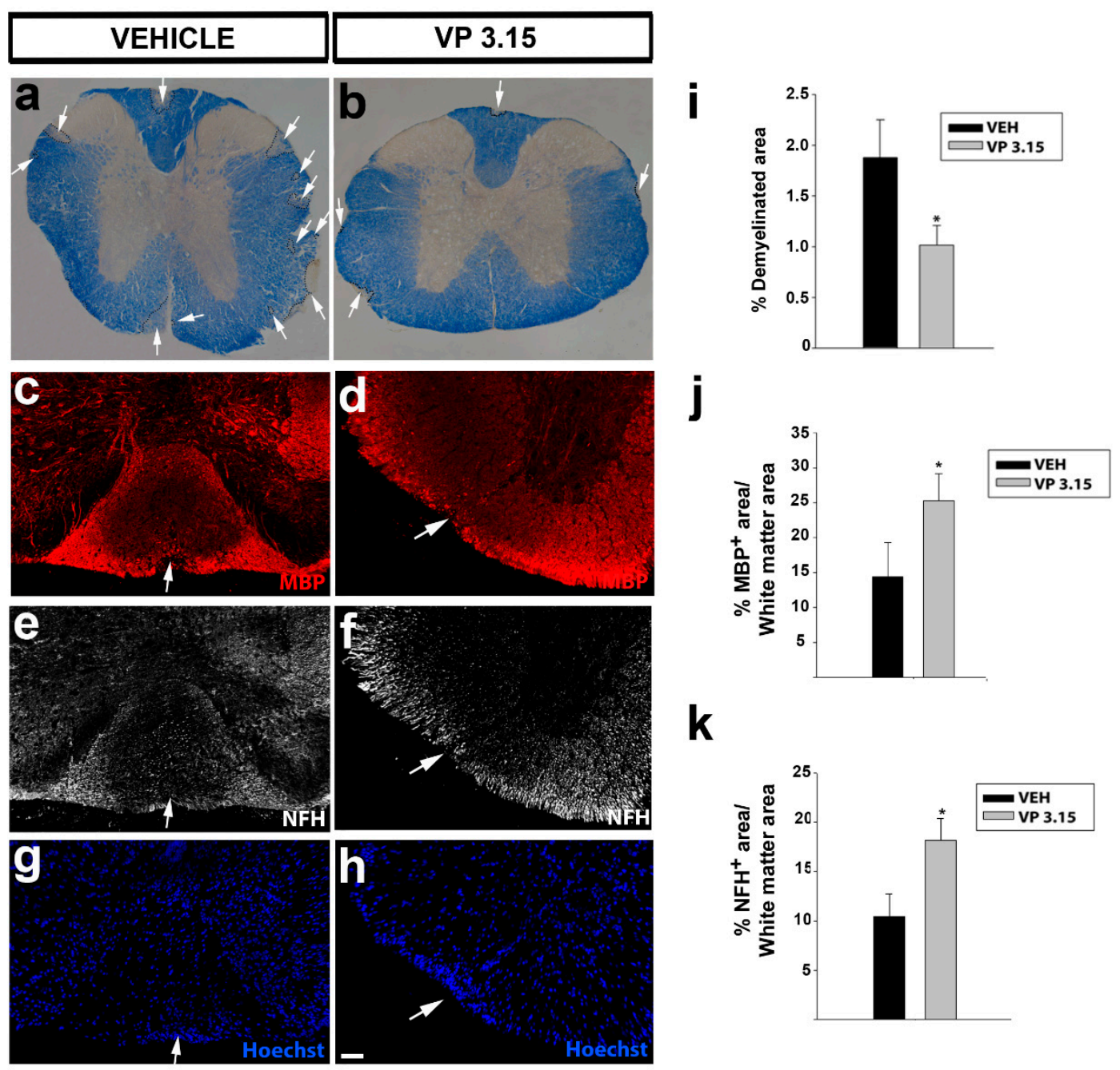

Figure 4. The spinal cord of VP3.15-treated mice presented a lower level of demyelination and axonal damage; (a,b): Panoramic views of the spinal cord stained with eriochrome cyanine of vehicle (a) and VP3.15-treated mice (b). The demyelinated area is delimited by the dashed line and arrows. Scale bar represents $200 \mu \mathrm{m}$ in $\mathbf{a}, \mathbf{b}$; (c-h): Detailed views of the spinal cords of vehicle (left) and VP3.15-treated mice (right), labelled for MBP (red), NFH (grey), and nuclei (Hoechst staining; blue). Lesions are identified as an accumulation of nuclei; (i): Graph showing a decreased percentage of demyelinated area respect to the white area in the VP3.15-treated mice; $(\mathbf{j}, \mathbf{k})$ : Histograms showing a significant increase in the percentage of both $\mathrm{MBP}^{+}(\mathrm{j})$ and $\mathrm{NFH}^{+}(\mathbf{k})$ area in the VP3.15-treated compared to the vehicle-treated mice. Scale bar represents 200 in $\mathbf{a}, \mathbf{b}$ and $50 \mu \mathrm{m}$ in $\mathbf{c}-\mathbf{h}$. Abbreviations: MBP = myelin basic protein; $\mathrm{NFH}=$ neurofilament heavy. Results of Student's $t$-test are represented as: ${ }^{*} p<0.05$. EAE-VEH: $n=7$; EAE-VP3.15: $n=10$.

These structural differences were observed in EAE-VEH and also when the treatment with VP3.15 was applied, that resulted in a growth in both parameters (Figure 5a,b). These facts may be attributed to a combination of the neuroprotective effect of VP3.15 probably due to its anti-inflammatory profile and its remyelination potential previously in different demyelinating animal models of MS, including EAE, and in vitro [35,36]. In addition to that, we found a direct and significant correlation between the normalized myelin basic 
protein (MBP) area and the normalized axonal area in both treatments, both in the optic nerve (Figure 5c; EAE-Veh: $r=0.559, p<0.01$; EAE-VP3.15: $r=0.546, p<0.01$ ) and the spinal cord (Figure 5d; EAE-Veh: $r=0.933, p<0.001$; EAE-VP3.15: $r=0.803, p<0.001$ ).

a

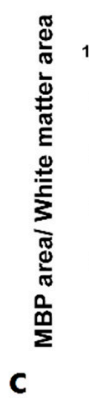

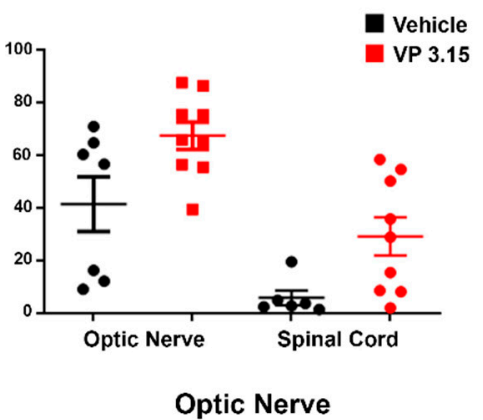

b
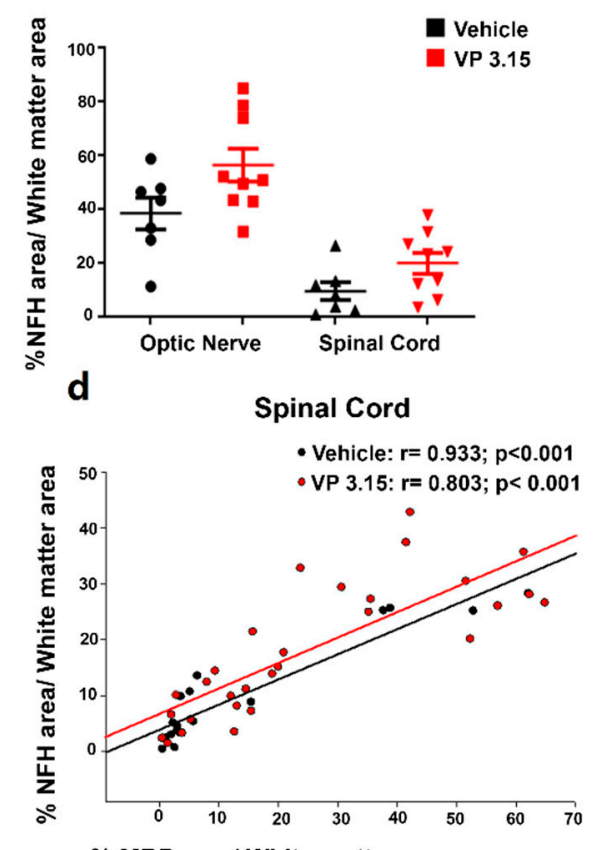

$\%$ MBP area/ White matter area

Figure 5. Axonal integrity is higher when the myelin is better preserved; $(\mathbf{a}, \mathbf{b})$ : Graphs showing the percentage of MBP (a) and NFH (b) area respect to the total white matter area between structures; $(\mathbf{c}, \mathbf{d})$ : Graphs showing the results of Pearson's correlation tests between the normalized MBP area and the normalized axonal area among treatments and in the optic nerve (c) and spinal cord (d). EAE-VEH: $n=7$; EAE-VP3.15: $n=10$.

We wondered if there was a relationship between the histological findings at the endpoint and the OCT recordings at different time points, so a study of partial correlations was performed. We assessed the correlation found between histological parameters (percentage of neurofilament heavy-chain (NFH) area, percentage of MBP area) and OCT findings (optic nerve width). Regarding the spinal cord, a significant partial correlation was found between the histological parameters when the OCT recording was maintained constant, both at the fifth and the final OCT recordings (Table 1).

However, there was no significant correlation between percentage of NFH and MBP in the nerve tissue when the OCT recordings were added to the partial correlation as the permanent variable (Table 1), suggesting that the optic nerve width is related to axon integrity.

Also, it is known that the dual PDE7-GSK3 inhibition by VP3.15 enhances murine and adult human OPC differentiation without affecting their survival or proliferation [35]. We inquired whether the remyelinating role and the neuroprotection on axons could be related to changes in the oligodendrocytes' lineage (Olig2 positive cells, Figure $6 \mathrm{~b}, \mathrm{f})$. In the optic nerve, a significant increase in the number of precursor cells, labelled as PDGFR $\alpha^{+}$cells (Figure 6a,e,i) and mature cells, identified as $\mathrm{CC}^{+}$cells (Figure 6c,g,j) was observed in the VP3.15-treated animals compared to the vehicle group. 
Table 1. Correlations between histological parameters and OCT data.

\begin{tabular}{|c|c|c|c|c|}
\hline & & & Veh $(n=7)$ & VP3.15 $(n=10)$ \\
\hline \multirow{9}{*}{ Spinal cord } & \multirow{5}{*}{ Pearson's coefficient $(r)$} & $\mathrm{MBP}$ area-NFH area & 0.933 & 0.803 \\
\hline & & $\begin{array}{c}\text { MBP area-optic nerve width at } \\
\text { fifth OCT }\end{array}$ & -0.212 & -0.024 \\
\hline & & $\begin{array}{l}\text { MBP area-optic nerve width at } \\
\text { endpoint OCT }\end{array}$ & -0.413 & -0.186 \\
\hline & & $\begin{array}{l}\text { NFH area-optic nerve width at } \\
\text { fifth OCT }\end{array}$ & -0.364 & -0.228 \\
\hline & & $\begin{array}{l}\text { NFH area-optic nerve width at } \\
\text { endpoint OCT }\end{array}$ & -0.533 & -0.362 \\
\hline & $\begin{array}{l}\text { Multiple correlation at fifth OCT } \\
\text { (two-tailed multicomparison test) }\end{array}$ & & 5.52246 & 3.78265 \\
\hline & $p($ fifth OCT $)$ & & $<0.01$ & $<0.05$ \\
\hline & $\begin{array}{l}\text { Multiple correlation at endpoint OCT } \\
\text { (two-tailed multicomparison test) }\end{array}$ & & 4.87270 & 3.56740 \\
\hline & $p$ (endpoint OCT) & & $<0.01$ & $<0.05$ \\
\hline \multirow{9}{*}{ Optic Nerve } & \multirow{5}{*}{ Pearson's coefficient (r) } & MBP area-NFH area & 0.559 & 0.546 \\
\hline & & $\begin{array}{c}\text { MBP area-optic nerve width at } \\
\text { fifth OCT }\end{array}$ & 0.579 & -0.385 \\
\hline & & $\begin{array}{l}\text { MBP area-optic nerve width at } \\
\text { endpoint OCT }\end{array}$ & 0.120 & 0.222 \\
\hline & & $\begin{array}{c}\text { NFH area-optic nerve width at } \\
\text { fifth OCT }\end{array}$ & 0.579 & 0.390 \\
\hline & & $\begin{array}{l}\text { NFH area-optic nerve width at } \\
\text { endpoint OCT }\end{array}$ & 0.077 & 0.202 \\
\hline & $\begin{array}{l}\text { Multiple correlation at fifth OCT } \\
\text { (two-tailed multicomparison test) }\end{array}$ & & 0.71492 & 1.39569 \\
\hline & $p($ fifth OCT) & & NS & NS \\
\hline & $\begin{array}{l}\text { Multiple correlation at endpoint OCT } \\
\text { (two-tailed multicomparison test) }\end{array}$ & & 1.33580 & 1.63117 \\
\hline & $p$ (endpoint OCT) & & NS & NS \\
\hline
\end{tabular}

Abbreviations: $n$ : mice number; NS: not significant.

In the spinal cord, the same effect, an increase in the precursor cells (Figure 7a,c,g,i,m) and mature oligodendrocytes (Figure $7 \mathrm{~b}, \mathrm{e}, \mathrm{h}, \mathrm{k}, \mathrm{n}$ ) was also observed. In all the cases, differences are related with oligodendrocytes' lineage (Olig2 positive cells, Figure $6 \mathrm{~d}, \mathrm{f}, \mathrm{j}, \mathrm{l})$.

We applied a two-way ANOVA to unravel the differences among treatments and structures, showing no significant differences for PDGFR $\alpha^{+}$cells (Figure 8a; $p=0.072$ ). We did find a significant difference between structures in the case of $\mathrm{CC}^{+}$cells, being the proportion lower in the optic nerve than in the spinal cord (Figure 8d; $p<0.001$ ). We then looked for a relationship between the myelin ( $\mathrm{MBP}^{+}$cells) and the two stages of the oligodendrocyte lineage under study (Figure $8 \mathrm{~b}, \mathrm{c}, \mathrm{e}, \mathrm{f})$ ). We found a significant and direct correlation in the case of $\mathrm{CC}^{+}$cells in the optic nerve of vehicle-treated EAE mice, (Figure 8b,e; EAE-Veh: $\mathrm{r}=0.470, p=0.0422$; EAE-VP3.15: $\mathrm{r}=0.254, p=0.22$ ). The relation between a lower proportion of $\mathrm{CC}^{+}$cells and higher levels of myelination that we previously showed could be explained by a difference in the rate of differentiation to mature phenotypes, that might be higher in the case of a highly myelinated tissue such as the optic nerve. 


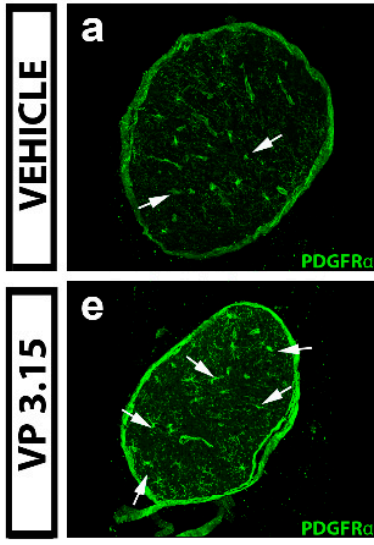

i

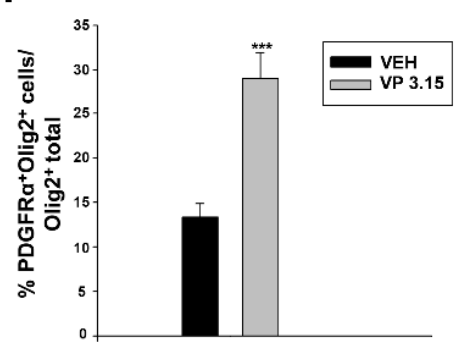

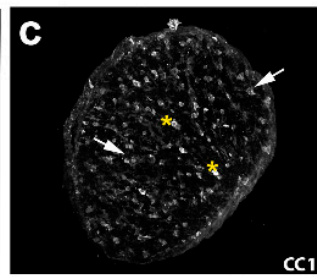
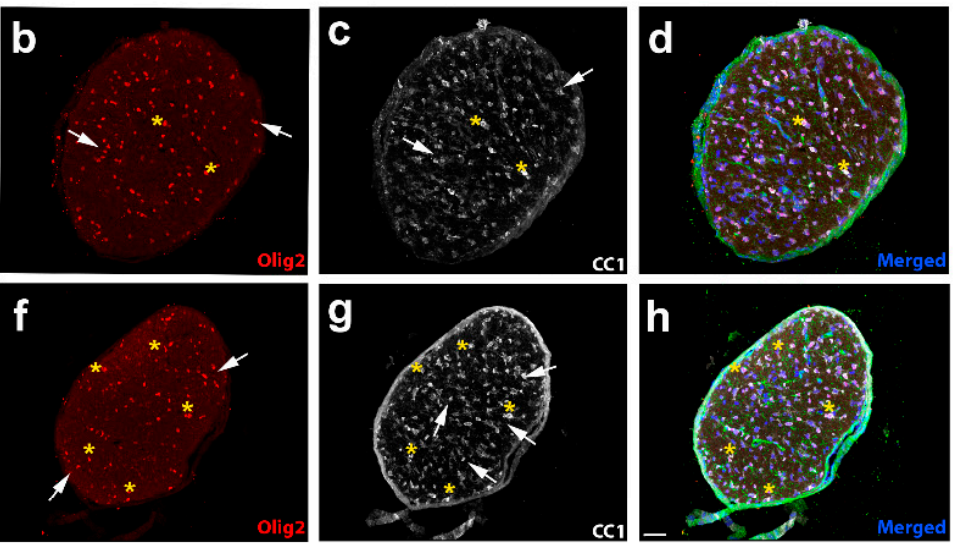

j

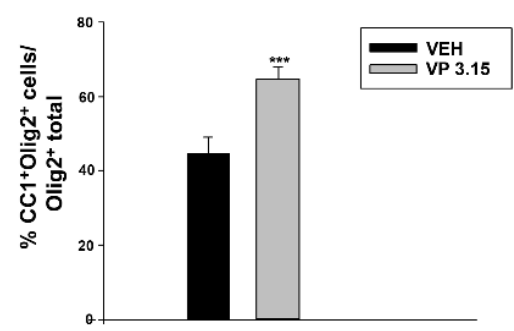

Figure 6. VP3.15 promotes the presence of both precursor and mature oligodendrocytes in optic nerve; (a-h): Detailed views of the optic nerve of vehicle (a-d) and VP3.15-treated mice (e-h), labelled for PDGFR $\alpha$ (green), Olig2 (red), CC1 (grey), and merged includes nuclei (Hoechst; blue). Arrows point to PDGFR $\alpha^{+} \mathrm{Olig} 2^{+}$cells and asterisks to $\mathrm{CC}^{+} \mathrm{Olig} 2^{+}$cells. Scale bar represents $50 \mu \mathrm{m}$ in $\mathbf{a}-\mathbf{h}$; $(\mathbf{i}, \mathbf{j})$ : Graphs showing the significant increase in the percentage of PDGFR $\alpha^{+} \mathrm{Olig} 2^{+}$cells $(\mathbf{i})$ and $\mathrm{CC} 1^{+}$ Olig2 ${ }^{+}$cells $(\mathbf{j})$ after the treatment with VP3.15 compared to the vehicle. Results of Student's t-test are represented as: ${ }^{* * *} p<0.001$. EAE-VEH: $n=7$; EAE-VP3.15: $n=10$.

\subsection{VP3.15 Treatment Modifies Microglial Activation State}

To get a deeper insight into the inflammatory component of the CNS at the end of VP3.15 treatment, we analyzed the composition of the microglial population, being divided into three groups: ramified, stellate-shaped, and amoeboid microglia [41,42]. In the optic nerve, there was an increase in the proportion of the stellate-shaped cells in the EAE-VP3.15 group compared to vehicle (Figure 9A,B,E; EAE-VEH $=0.043 \pm 0.007 \%$; EAE-VP $3.15=0.082 \pm 0.006 \%$ ), while the other two subpopulations remained similar between groups (Figure 9A,B,E; ramified microglia: EAE-VEH $=0.004 \pm 0.010 \%$; EAE-VP3.15 $=0.045 \pm 0.006 \%$; amoeboid microglia: EAE-VEH $=0.044 \pm 0.0147 \%$; EAE-VP3.15 $=0.027 \% \pm 0.014 \%$ ). Regarding the spinal cord, the microglial population was enriched in stellate-shaped cells in the VP3.15-treated mice in contrast to the vehicle-treated group (Figure 9C,D,F; EAE-VEH $=0.025 \pm 0.003 \%$; EAE-VP3.15 $=0.045 \pm 0.002 \%$ ), being the amoeboid subpopulation significantly decreased (Figure 9C,D,F; EAE-VEH $=0.004 \pm 0.003 \%$; EAE-VP3.15 $=0.266 \pm 0.003 \%$ ). Finally, that of the ramified microglia remained constant in both groups, as in the optic nerve. Altogether, our present results show that the neuroprotective profile of VP3.15 is accompanied by a switch of the microglial content to anti-inflammatory phenotypes, underlying the important role of the immunomodulatory effects of this drug candidate. 

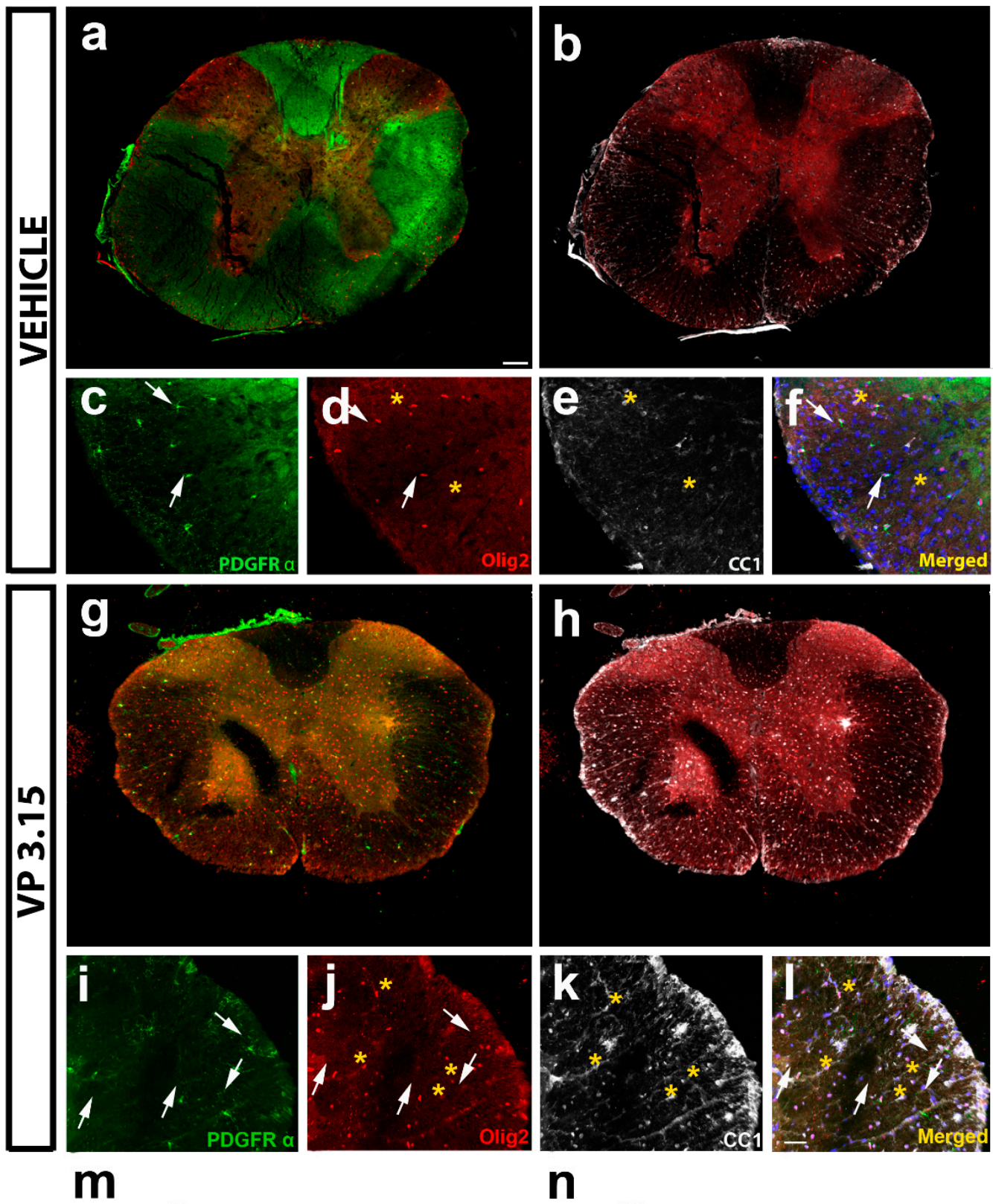

m

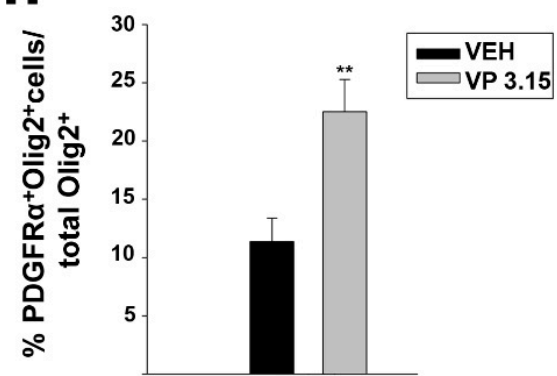

n

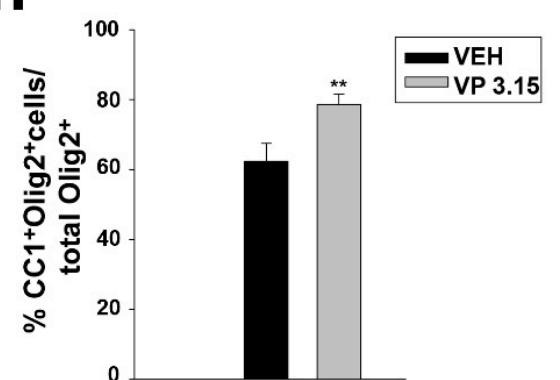

Figure 7. The treatment of EAE mice with VP3.15 promotes the presence of both precursor and mature oligodendrocytes in spinal cord; (a-1): Representative panoramic views (a,b and $\mathbf{g}-\mathbf{h})$ and detailed images (c-f and $\mathbf{i}-\mathbf{l})$ of the spinal cords of vehicle $(\mathbf{a}-\mathbf{f})$ or VP3.15 treatment $(\mathbf{g}-\mathbf{l})$. Cells are labelled for PDGFR $\alpha$ (green), Olig2 (red), CC1 (grey), and merged, that includes nuclei (Hoechst; blue). Arrows point to PDGFR $\alpha^{+}$Olig2 ${ }^{+}$cells, and asterisks to $\mathrm{CC}^{+} \mathrm{Olig}^{+}$cells. Scale bar in $\mathbf{a}, \mathbf{b}$, $\mathbf{g}$, and $\mathbf{h}$ represents $200 \mu \mathrm{m}$ and the rest represents $50 \mu \mathrm{m} ;(\mathbf{m}, \mathbf{n})$ : Graphs showing the significant increase in the percentage of PDGFR $\alpha^{+} \mathrm{Olig} 2^{+}$cells $(\mathbf{m})$ and Olig2 ${ }^{+} \mathrm{CC} 1^{+}$cells $(\mathbf{n})$ after the treatment with VP3.15 compared to the vehicle. Results of Student's $t$-test are represented as: ${ }^{* *} p<0.01$. EAE-VEH: $n=7$; EAE-VP3.15: $n=10$. 

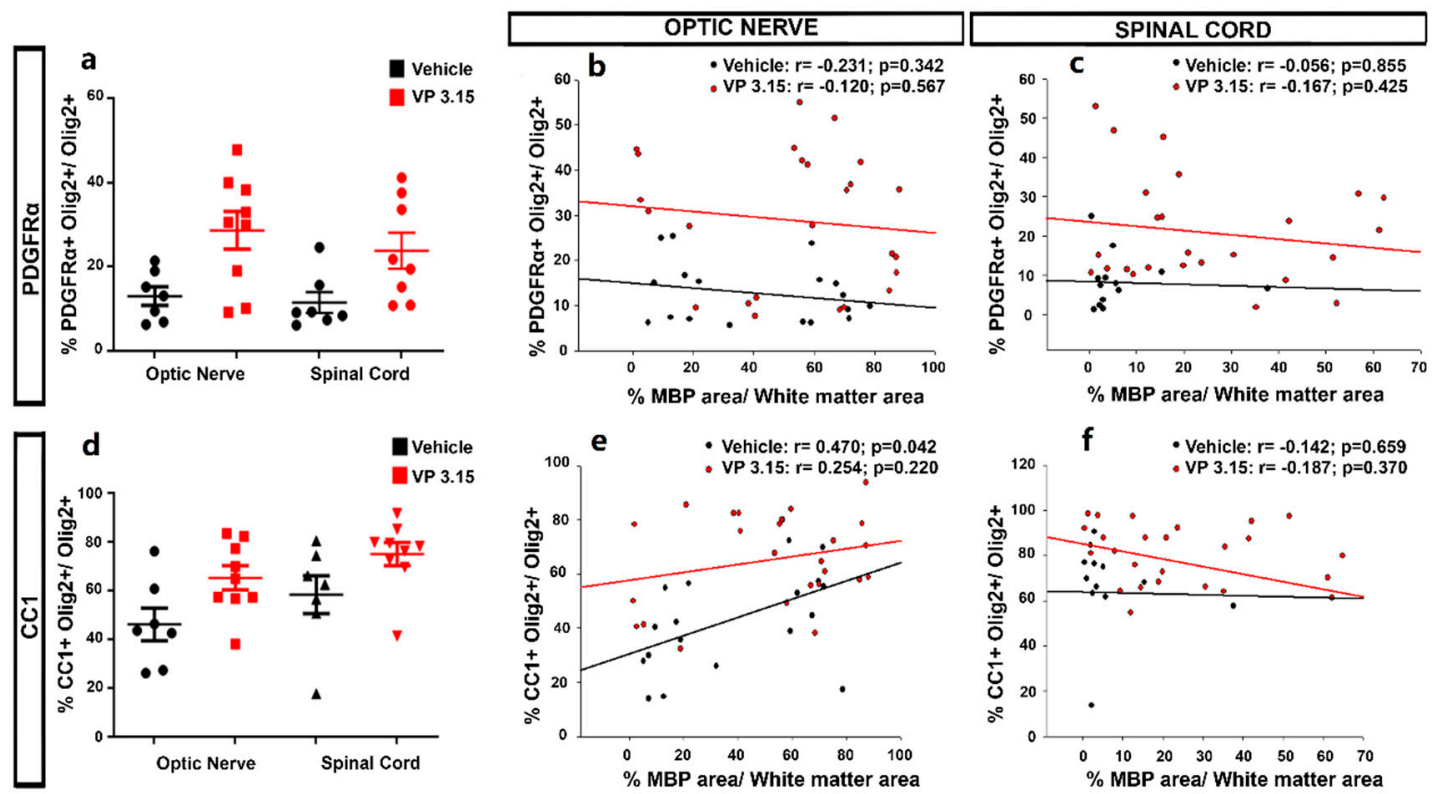

Figure 8. The maturation state of oligodendrocytes is related to the myelin preservation in the optic nerve; (a-d): Graphs showing the different levels of precursor $\left(\mathrm{PDGFR}^{+} ; \mathbf{a}\right)$ and mature cells $\left(\mathrm{CC} 1^{+}\right.$cells; $\left.\mathbf{d}\right)$ between structures; $(\mathbf{b}, \mathbf{c})$ : Graphs showing the correlation between the normalized MBP area and the percentage of PDGFR $\alpha^{+}$Olig2 $2^{+}$cells in both treatments and in the optic nerve (b) and spinal cord (c); (e,f): Graphs showing the results of Pearson's correlation between the normalized MBP area and the CC1+ Olig2 ${ }^{+}$cells in both treatments and in the optic nerve (e) and spinal cord (f). EAE-VEH: $n=7$; EAE-VP3.15: $n=10$.
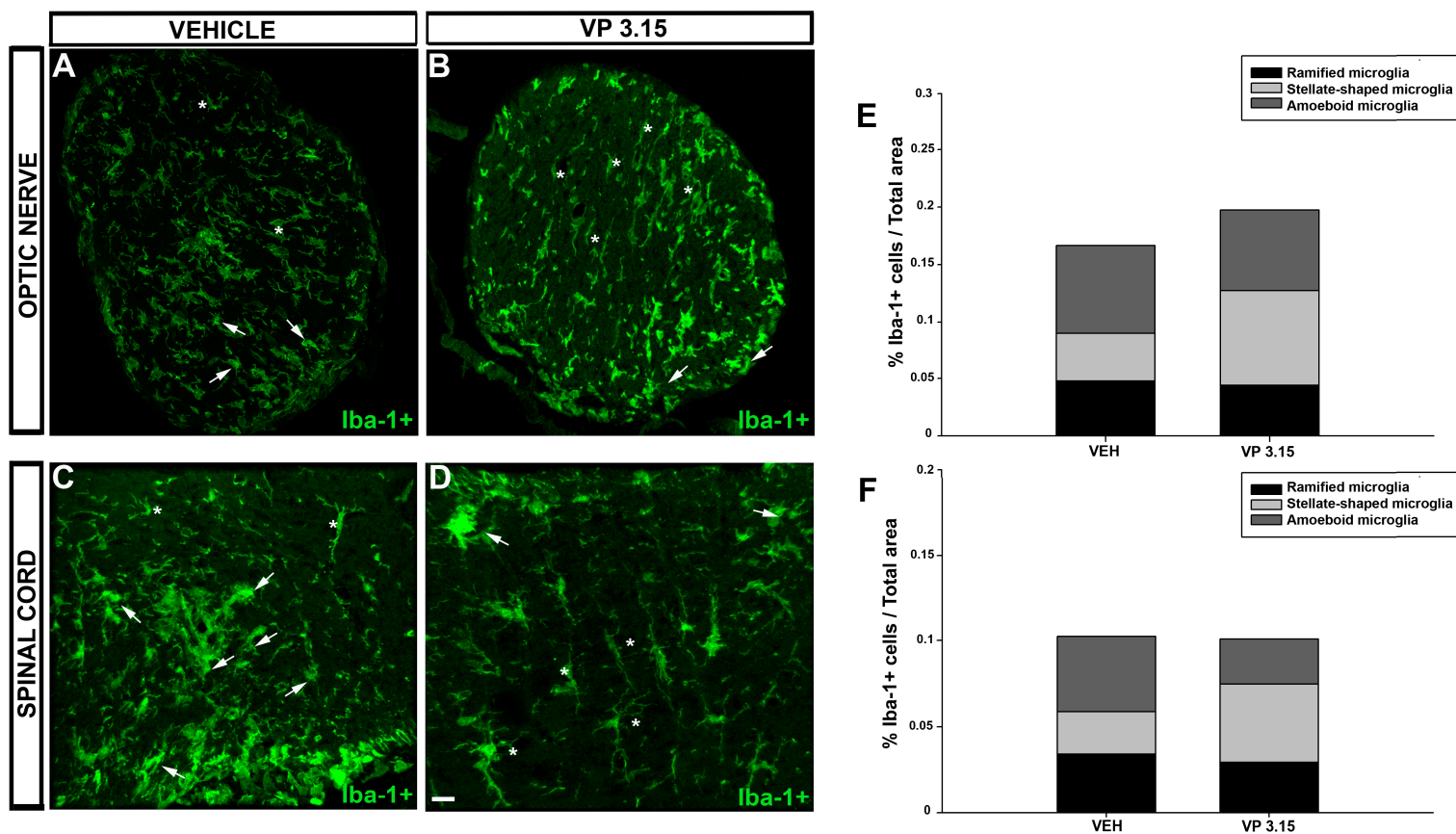

Figure 9. Effects of VP3.15 on Iba- $1^{+}$in spinal cord and optic nerve; (A-D): Detailed views of the optic nerve of vehicle (A) and VP 3.15-treated mice (B) and the spinal cord of vehicle (C) and VP3.15-treated mice (D), labelled for Iba- $1^{+}$cells (green). Arrows point to amoeboid microglia cells and asterisks mark stellated-shaped microglial cells; (E,F): Stacked histograms of the spinal cord (E) and optic nerve (F) content in microglia. In both cases, whereas the ramified microglia remain constant in the EAE-VP3.15 and the EAE-VEH group, the proportion of a stellated-shaped and amoeboid microglia is the opposite, being higher in the former. Scale bar represents $50 \mu \mathrm{m}$ in A-D. EAE-VEH: $n=7$; EAE-VP3.15: $n=10$. 


\section{Discussion}

The development of effective remyelinating approaches is still an unmet challenge of neurology. In this frame, our study adds new evidence on the usefulness of OCT as a non-invasive [42] and easy technique to monitor MS evolution with remyelinating agents. Furthermore, we have provided more details on the potential of VP3.15 as a useful drug candidate for the future therapy of MS.

To the best of our knowledge, this is the first work that correlates the morphological characteristics of optic nerve in vivo (OCT) with demyelination/neurodegeneration and remyelination in an animal model of MS, through histological analysis performed at the endpoint of the study. Some of our findings, such as the decreased thickness of RNFL and ganglion cell layer (GCL) in MS have already been described [43-45]. However, these studies were not repeated at different times of evolution, nor were corroborated with postmortem observations, conferring to our present study part of its uniqueness. We additionally propose that, in spite of the limitations of its observation via OCT, the width of the optic nerve papilla would be very effective to monitor the demyelination/remyelination dynamics of the entire optic nerve and the parenchymatous CNS, as seen by multiple correlations found in our study. Given the parallelism between the degree of myelin preservation/regeneration and the protection of axons observed in our current study, we propose that OCT could also be useful to monitor the overall neurodegeneration of neurons in the CNS. Techniques allowing the visualization of glia in response to drug discovery in MS is by itself a challenge [46] and the absolute safety of OCT, together with its growing implementation in monitoring MS patients for other purposes, represents a major opportunity for current and future developments in the field.

The first report that showed positive effects of a remyelinating agent for MS patients in clinical trials [8] raised some hope that has been tempered with the evidence that point to the need of further remyelinating treatments. These compounds could complement the currently available therapeutic arsenal to treat MS with different agents that would result in different combinations with immunomodulators to find the best match for the clinical idiosyncrasy of each MS patient [47]. This is even more evident after recent demonstrations showing that molecular changes in MS have an impact on the (re)myelinating scenario in the adult CNS, including changes in oligodendroglial populations [48-52]. Thus, we decided to perform the study here described using the remyelinating agent VP3.15 as pharmacological tool. In agreement with previous reports performed in different experimental paradigms and models $[35,36,38]$ our results showed that the treatment with VP3.15 was apparent from the very first moment of application in vivo, ameliorating the clinical score, the score fraction, and the thinning of the optic nerve measured by OCT. This is the first time where measures from OCT have been correlated with neurological clinical scores in the EAE model pointing to a useful non-invasive technique to follow the pathology with great translational potential.

The anti-inflammatory in vivo effect of VP3.15 seems to rely on its potential to diminish reactive (ameboid) microglia and it is in agreement with previous results from primary microglia and astrocytes cell cultures [34]. Microglia have traditionally been recognized as the cells that mediate the inflammatory response in the CNS. However, it is currently known that ramified microglia, also called quiescent microglia, are involved in the structural and functional plasticity of neurons and, once polarized into anti-inflammatory phenotypes, are sine qua non condition for debris phagocytosis and effective remyelination [5,41,53-57]. Our present data reflects that the majority of microglia in both structures was stellate and there was only a reduction of ameboid forms in the spinal cord, which could be related to its proximity to the tail, where the immunization is performed in this model, and therefore where the myelin recovers first. This could also be reflected in the results obtained with the partial correlation (see above).

Although we cannot discard the indirect effect of anti-inflammation, our current work, together with our previous reports $[35,36]$, confirms the combined remyelinating-plusneuroprotective-plus-anti-inflammatory effect of VP3.15, thus its potential to treat MS 
should be tested in clinical trials. To date, there are no treatments with confirmed activity on these three incontournable aspects of MS pathogenesis $[9,47,58,59]$, confirming the inhibition of phosphodiesterases and GSK-3 $\beta$ as a big hope for the treatment of MS $[60,61]$.

Altogether, our current results, apart from supporting OCT as a useful non-invasive technique for the dynamic evaluation of retinal and optic nerve changes in EAE mice, point to the correlation between demyelinating/remyelinating events in the optic nerve and the parenchymatous CNS. This association is corroborated by the partial correlations described here. While the first should be enough to include OCT in the preclinical studies on the search of effective remyelinating approaches, the second could be very useful to check the evolution of MS patients and the effectiveness of the treatments that they receive now, and when the desired remyelinating therapies will be a reality. This would be, at least, applicable to MS patients where the vision/optic nerve is affected by the disease, which is known to be among the more frequent localizations of demyelination [62-65] and it has been very recently reported as an underestimated problem [66]. It is true that our present results allowed us to measure parenchymatous CNS myelin and changes in the oligodendroglial lineage only at the end of the study, but it is also true that performing OCTs to monitor treatments in MS patients will be faster and more affordable than monitoring via sequential MRIs. Like in most diseases, the finding of new useful biomarkers for MS represents a major goal for current neurology [67].

In summary, the present work provides evidence to support OCT as a valuable methodology to follow the MS pathology evolution in vivo, finding a clear correlation between events in the optic nerve and in the spinal cord. Furthermore, the relevant pharmacological profile of VP3.15 as a potential disease-modifying agent for MS with a combined remyelinating-plus-neuroprotective-plus-anti-inflammatory effect has been confirmed. The translation of these results to the clinic may open a new avenue to follow the efficacy of remyelinating drugs on patients and underscore the relevance of future clinical trials for remyelinating drugs such as VP3.15.

\section{Material and Methods}

\subsection{Induction of EAE and Treatment}

Six-week-old female C57 /BL6 mice, bred at the CIB Margarita Salas-CSIC, were induced for EAE as has been done by our research group for a decade [68-71]. Mice were divided into three experimental groups as follows: EAE-VP3.15 (compound-treated EAE animals; $n=10$ ), EAE-Vehicle (non-treated EAE animals; abbreviated as EAE-Veh; $n=7$ ) and SHAM (same procedure as EAE animals except the MOG injection; $\mathrm{n}=13$ ). After being anesthetized with xilacine and ketamine $\left(\right.$ Xilagesic $^{\circledR} 20 \mathrm{mg} / \mathrm{mL}$, Calier; Ketolar ${ }^{\circledR}$ $37 \mathrm{mg} / \mathrm{kg}$, Pfizer) chronic progressive EAE was induced by subcutaneous immunization with $250 \mu \mathrm{g}$ of myelin oligodendrocyte glycoprotein (MOG35-55 peptide: GenScrip HK Limited, Hong Kong) emulsified in complete Freund's adjuvant (CFA) containing 4 mg of heat inactivated Mycobacterium tuberculosis (BD Biosciences, Franklin Lakes, NJ, USA) and at a final volume of $200 \mu \mathrm{L}$. Sham-operated animals received phosphate-buffer saline (PBS) instead of the MOG peptide. Both immunized and SHAM mice were administered with Pertussis toxin (400 ng/mouse, Sigma-Aldrich, St. Louis, MO, USA), injected intravenously through the tail vein on the day of immunization and $48 \mathrm{~h}$ later. EAE was scored clinically on a daily basis in a double-blind manner as follows: 0, no detectable signs of EAE; 1, paralyzed tail; 2, weakness or unilateral partial hindlimb paralysis; 3, complete bilateral hindlimb paralysis; 4 , total paralysis of forelimbs and hindlimbs; and 5, death. We established the peak of the symptoms as the second day of maximal clinical score reached by the mouse, being higher than 2 and the average 2.5. From this point onwards, the animals classified as EAE-VP3.15 were intraperitoneally injected a daily dose of $10 \mathrm{mg} / \mathrm{kg}$ of VP3.15 compound, synthesized in the CIB Margarita Salas facilities following synthetic procedures previously described [34] and EAE-VEH were intraperitoneally injected a daily dose of vehicle. VP3.15 was resuspended in $100 \mathrm{mg} / \mathrm{mL}$ in DMSO diluted 1:50 in a solution of $5 \%$ Tocrisolve (Tocris ${ }^{\circledR}$, Minneapolis, MN, USA) to a maximal final volume of 
$250 \mu \mathrm{L}$ and the treatment was over 21 days. The EAE-VEH and SHAM animals were intraperitoneally injected with the vehicle (DMSO diluted in a solution of Tocrisolve). The exponential expression of VP3.15 healing ability was calculated using XMGrace, taking the maximal clinical score (CS max) as starting point. In order to compare both groups we normalized the score at every given time point by the maximal score $\left(\mathrm{S}_{\mathrm{f}}\right.$; score fraction). Thus, CS/CSmax decayed from 1 to a final plateau value, that infers the remaining score at long/infinite times $(S \infty)$.

All experiments were performed in compliance with the "Principles of Laboratory Animal Care" (NIH publication No. 86-23, revised 1985), the European guidelines for animal research (European Communities Council Directives 2010/63/EU, 90/219/EEC, Regulation (EC) No. 1946/2003), and with the Spanish National and Regional Guidelines for Animal Experimentation and the Use of Genetically Modified Organisms (RD 53/2013 and 178/2004, Ley 32/2007 and9/2003, Decreto 320/2010); and approved by the institutional ethical committees (Ethics Committees at the Consejo Superior de Investigaciones Científicas and Comunidad de Madrid).

\subsection{OCT Data Acquisition and Analysis}

For OCT analysis, a Spectralis OCT set up (Heidelberg Engineering GmbH৫, Germany) was used. Both eyes of the animals were analyzed at seven time points: at the baseline (before immunization), onset, peak, and every five days until sacrifice (Figure 1a). The mice were anesthetized with Ketamine $37 \mathrm{mg} / \mathrm{kg}$ (Ketolar ${ }^{\circledR} 50 \mathrm{mg} / \mathrm{mL}$, Pfizer, Madrid, Spain) and Medetomidine $10 \mathrm{mg} / \mathrm{kg}$ (Domtor ${ }^{\circledR} 1 \mathrm{mg} / \mathrm{mL}$, Ecuphar, Barcelona, Spain) and the eye pupil was dilated with atropine $1 \%$ (Colircusi $^{\circledR}$, Novartis Farmacéutica, S.A., Madrid, Spain) for a better visualization. The eye under analysis was protected with a contact lens and the other with saline or artificial teardrops (Artific ${ }^{\circledR} 3.2 \mathrm{mg} / \mathrm{mL}$, Bausch \& Lomb S.A., Madrid, Spain) to avoid drying. Once immobilized, the eye bottom was focused (0.5-1.5 optic diopters) and images were captured in a high-resolution mode in two scanning modalities: radial (six radius per image) and longitudinal. The automatic real time (ART) mode was set at 45 and images were captured with a quality higher than $40 \%$. The follow-up tool was used so the images for the mice were acquired at exactly the same area each time. Animals were awakened with Antisedan ${ }^{\circledR} 5 \mathrm{mg} / \mathrm{mL}$ (Ecuphar, Barcelona, Spain). The area, perimeter, and width of the optic disc were analyzed with the Image J software (Image J). For the retinal layer thickness analysis, five points separated by $50 \mu \mathrm{m}$ were taken at both sides of the optic nerve papilla per eye. Retinal nerve fiber layer (RNFL), ganglion cell layer (GCL), and inner plexiform layer (IP) thickness were measured alone or combined and referred to the total retina thickness using the segmentation provided by the Spectralis OCT software. As we did not find a difference between the right and left eyes, the results are reported as a mean \pm standard error of the mean (SEM) of both eyes taken together. Data were taken from every single time point. The baseline OCT values were taken from animals before the immunization procedure.

\subsection{Tissue Section}

All the histological studies were made at the endpoint of the experiment, that was 21 days after treatment started. For histology, animals were euthanized with a lethal dose of pentobarbital (EUTANAX ${ }^{\circledR}$, Fatro Ibérica, Barcelona, Spain). All animals were perfused transcardially with $4 \%$ paraformaldehyde in $0.1 \mathrm{M}$ phosphate buffer (PB, pH 7.4). The spinal cords and optic nerves were dissected out and post-fixed in the same fixative for $4 \mathrm{~h}$ at room temperature (RT). After a progressive immersion in $10 \%, 20 \%$, and $30 \%(w / v)$ sucrose diluted in $0.1 \mathrm{M} \mathrm{PB}(\mathrm{pH} 7.4)$ for $12 \mathrm{~h}$, coronal cryostat sections $(20 \mu \mathrm{m}$ thick: Leica, Nussloch, Germany) were thaw-mounted on Superfrost ${ }^{\circledR}$ Plus slides with an embedding medium for frozen samples named OCT (Tissue-Tek ${ }^{\circledR}$, Sakura Finetek Spain, Barcelona, Spain). In the case of the optic nerve, the medium used was blue TFM ${ }^{\mathrm{TM}}$ (Tissue Freezing Medium, Electron Microscopy Sciences, VWR, Barcelona, Spain). 


\subsection{Eriochrome Cyanine Staining}

For myelin analysis, the sections were dried for $2 \mathrm{~h}$ at $\mathrm{RT}$ and for $1.5 \mathrm{~h}$ at $37^{\circ} \mathrm{C}$ in a slide warmer. The slides were then placed in a container with acetone for $5 \mathrm{~min}$ at RT and air-dried for $30 \mathrm{~min}$. The sections were stained in $0.2 \%$ eriochrome cyanine (EC) solution for $30 \mathrm{~min}$ and differentiated in 5\% iron aluminum and borax-ferricyanide for 10 and $5 \mathrm{~min}$, respectively, briefly rinsing under tap and distilled water between each step. Myelin is stained in blue and cell bodies in whitish [72].

\subsection{Immunohistochemistry}

Sections were first air-dried for $1 \mathrm{~h}$ at RT. After several rinses with PB, the sections were pre-treated for 15 min with $10 \%$ methanol in PB and washed three times with PBS for 10 min each time. In the case of myelin basic protein (MBP) labelling, sections were delipidated with a battery of ethanol-increasing concentrations $(25 \%, 75 \%, 95 \%$, and $100 \%)$ and later step-back rehydration for the following steps. Sections were then pre-incubated for $1 \mathrm{~h}$ at RT in incubation buffer: $5 \%$ normal donkey serum (EMD Millipore, Billerica, MA, USA) and $0.2 \%$ Triton X-100 (Sigma-Aldrich, Madrid, Spain) diluted in PBS. Immunohistochemistry was performed by incubating the sections overnight at $4{ }^{\circ} \mathrm{C}$ with the primary antibodies (Table 2) diluted in incubation buffer. After rinsing, the sections were incubated with the corresponding fluorescent (1:1000, Invitrogen, Paisley, UK) secondary antibodies in the incubation buffer for $1 \mathrm{~h}$ at RT. In all cases, cell nuclei were stained with Hoeschst 33342 $(10 \mu \mathrm{g} / \mathrm{mL}$, Sigma-Aldrich, Madrid, Spain) and the sections were mounted with coverslips in Fluoromount-G (Southern Biotech, Birmingham, AL, USA).

Table 2. List of antibodies used in this study.

\begin{tabular}{|c|c|c|c|c|c|c|c|}
\hline Antibody & Target & $\begin{array}{l}\text { Cellular } \\
\text { Location }\end{array}$ & Dilution & Host Species & Class & Manufacturer & Antibody ID \\
\hline MBP & Myelin & $\begin{array}{c}\text { Plasma } \\
\text { Membrane }\end{array}$ & $1: 500$ & Rat & $\begin{array}{l}\text { Monoclonal } \\
\text { clone } 12\end{array}$ & Biorad & aa $82-87$ \\
\hline NFH & Neurons/ Axons & Cell Body & 1:1000 & Rabbit & Polyclonal & Abcam & $\mathrm{Ab} 8135$ \\
\hline Iba-1 & Microglia & $\begin{array}{c}\text { Plasma } \\
\text { membrane }\end{array}$ & $1: 500$ & Guinea pig & Polyclonal & Synaptic Systems & 234004 \\
\hline PDGFR $\alpha$ & OPCs & $\begin{array}{c}\text { Plasm } \\
\text { membrane }\end{array}$ & $1: 200$ & Goat & Polyclonal & RD Systems & AF 1062 \\
\hline $\mathrm{CC} 1$ & $\begin{array}{c}\text { Mature } \\
\text { oligodendrocytes }\end{array}$ & Cell body & $1: 200$ & Mouse & $\begin{array}{l}\text { Monoclonal } \\
\text { clone CC1 }\end{array}$ & $\begin{array}{l}\text { Merck } \\
\text { Millipore }\end{array}$ & OP 80 \\
\hline Olig2 & $\begin{array}{l}\text { Oligodendrocyte } \\
\text { lineage }\end{array}$ & nucleus & $1: 200$ & Rabbit & Polyclonal & $\begin{array}{c}\text { Merck } \\
\text { Millipore }\end{array}$ & AB 9610 \\
\hline
\end{tabular}

Abbreviations: $\mathrm{MBP}=$ myelin binding protein; NFH = neurofilament heavy polypeptide; PDGFR $\alpha=$ platelet-derived growth factor receptor $\alpha$; OPCs $=$ oligodendrocyte precursor cells.

\subsection{Tissue Analysis and Cell Quantification}

Eriochrome cyanine-stained sections were analyzed by acquiring $20 \times$ reconstructed images with a color camera of a Zeiss microscope (Leica DM 750) in the Microscopy Facility of Cajal Institute-CSIC and the total number of lesions was quantified using the Image J software. For all immunohistochemistry, pictures were acquired with a confocal SP5 microscope (Leica) located at the Microscopy Service of Cajal Institute-CSIC (20 $\mu \mathrm{m}$ z-stack at $3 \mu \mathrm{m}$ intervals, $40 \times$ objective; and for microglia, $20 \mu \mathrm{m}$ z-stack at $0.5 \mu \mathrm{m}$ intervals, $63 \times$ objective) and cells were counted avoiding their overlap. The myelin basic protein (MBP) and the neurofilament heavy (NFH) labelling were quantified by measuring the fluorescence area using the Image J software.

The total number of cells within the CNS tissue was assessed using microscopy image analysis software (IMARIS, Oxford, UK), counting cells in three sections of spinal cord from each animal, under a user-defined threshold of fluorescence. In the case of the 
oligodendrocytes, we quantified the PDGFR $\alpha^{+} \mathrm{Olig} 2^{+}$and the $\mathrm{CC} 1^{+} \mathrm{Olig} 2^{+}$. Total Iba- $1^{+}$ cells were sorted out into three morphological subtypes (ramified microglia, stellate-shaped microglia, and amoeboid microglia cells) [73-75]. Briefly, ramified microglia have a small and rounded cell body with processes in the form of tree branches; the stellate-shaped microglia have a large oval cell body with less extensive and thick processes; and the amoeboid microglia does not have a completely rounded cell body and its processes are not as well-defined.

\subsection{Statistical Analysis}

The data were expressed as the mean \pm SEM and analyzed with Sigma Plot version 11.0 (Systat Software, San Jose, CA, USA). Student's $t$-test was used to compare pairs of the different groups of mice with a Mann-Whitney U test for non-parametric data. A two-way ANOVA with multiple comparisons using a Bonferroni post-hoc test was used for the comparison of three groups (EAE-VP3.15 vs. EAE-VEH vs. SHAM), obtaining the area under the curve. Correlation analyses were performed using the Pearson's correlation test. Multiple correlations were made using the Pearson's correlation test, and applying the following formula, as previously described [76]:

$$
t=\frac{r_{12.3} \sqrt{\mathrm{n}-3}}{\sqrt{1-r^{2} 12.3}}
$$

Minimal statistical significance was set at $p<0.05$, and illustrated as * or \# $(p<0.05)$, ** or \#\# $(p<0.01)$, and ${ }^{* * *}$ or \#\#\# $(p<0.001)$.

Author Contributions: Conceptualization, A.M. and F.d.C.; methodology, R.B.-F., C.G., E.J.d.l.R., F.d.C., and A.M.; formal analysis, R.B.-F., C.M.-J., C.G., E.J.d.l.R., A.M., and F.d.C.; investigation, R.B.-F. and C.M.-J.; resources, A.M. and F.d.C.; data curation, E.J.d.l.R., A.M., and F.d.C.; writingoriginal draft preparation, R.B.-F. and C.M.-J.; writing—review and editing, C.G., E.J.d.l.R., A.M., and F.d.C.; supervision, C.G., A.M., and F.d.C.; funding acquisition, A.M. and F.d.C. All authors have read and agreed to the published version of the manuscript.

Funding: This research was funded by Asociación Española de Esclerosis Múltipe- Confederación Española de Personas con Discapacidad Física y Orgánica (AEDEM-COCEMFE; Dña. Angela Sastre legacy) and Ministerio de Ciencia, Innovación y Universidades (grant no. SAF2015-72325-EXP, SAF2016-77575-R to F.d.C and RD16-0019 to F.d.C).

Institutional Review Board Statement: The study was conducted according to the guidelines of the Declaration of Helsinki, and approved by the CSIC Ethics Committee (protocol code PROEX 143/16 21/07/2016).

Data Availability Statement: The data presented in this study are available on request from the corresponding author.

Acknowledgments: The authors would like to thank the invaluable help of Sergio Casas from Instituto Cajal with the IMARIS equipment, the animal facility at CIB Margarita Salas for their technical assistance and support, Eduardo Sanz from Universidad Complutense for the exponential adjustment and Carmen Hernández and Belén García from the Confocal Microscopy facility at Instituto Cajal for their help in image acquisition. We want to dedicate this work to our friend Gerardo García Perales, unforgettable President of AEDEM-COCEMFE, who always fought to improve the quality of life of $\mathrm{mS}$ patients and supported research. We acknowledge support of the publication fee by the CSIC Open Access Publication Support Initiative through its Unit of Information Resources for Research (URICI).

Conflicts of Interest: The authors declare no conflict of interest.

\section{References}

1. Browne, P.; Chandraratna, D.; Angood, C.; Tremlett, H.; Baker, C.; Taylor, B.V.; Thompson, A.J. Atlas of Multiple Sclerosis 2013: A growing global problem with widespread inequity. Neurology 2014, 83, 1022-1024. [CrossRef] [PubMed]

2. Sospedra, M.; Martin, R. Immunology of multiple sclerosis. Annu. Rev. Immunol. 2005, 23, 683-747. [CrossRef] [PubMed] 
3. Vogel, D.Y.S.; Vereyken, E.J.F.; Glim, J.E.; Heijnen, P.D.A.M.; Moeton, M.; van der Valk, P.; Amor, S.; Teunissen, C.E.; van Horssen, J.; Dijkstra, C.D. Macrophages in inflammatory multiple sclerosis lesions have an intermediate activation status. J. Neuroinflammation 2013, 10, 809. [CrossRef] [PubMed]

4. Clemente, D.; Ortega, M.C.; Melero-Jerez, C.; de Castro, F. The effect of glia-glia interactions on oligodendrocyte precursor cell biology during development and in demyelinating diseases. Front. Cell. Neurosci. 2013, 7, 1-15. [CrossRef] [PubMed]

5. Miron, V.E.; Boyd, A.; Zhao, J.-W.; Yuen, T.J.; Ruckh, J.M.; Shadrach, J.L.; Van Wijngaarden, P.; Wagers, A.J.; Williams, A.; van Wijngaarden, P.; et al. Europe PMC Funders Group M2 microglia / macrophages drive oligodendrocyte differentiation during CNS remyelination. Nat. Neurosci. 2013, 16, 1211-1218. [CrossRef] [PubMed]

6. Luo, C.; Jian, C.; Liao, Y.; Huang, Q.; Wu, Y.; Liu, X.; Zou, D.; Wu, Y. The role of microglia in multiple sclerosis. Neuropsychiatr. Dis. Treat. 2017, 13, 1661-1667. [CrossRef]

7. Hart, F.M.; Bainbridge, J. Current and emerging treatment of multiple sclerosis. Am. J. Manag. Care 2016, 22, s159-s170.

8. Green, A.J.; Gelfand, J.M.; Cree, B.A.; Bevan, C.; Boscardin, W.J.; Mei, F.; Inman, J.; Arnow, S.; Devereux, M.; Abounasr, A.; et al. Clemastine fumarate as a remyelinating therapy for multiple sclerosis (ReBUILD): A randomised, controlled, double-blind, crossover trial. Lancet 2017, 390, 2481-2489. [CrossRef]

9. de Castro, F.; Josa-Prado, F. Regulation of oligodendrocyte differentiation: New targets for drug discovery in remyelination. Emerg. Drugs Targets Mult. Scler. 2019, 10, 222-240.

10. Zhang, Y.; Argaw, A.T.; Gurfein, B.T.; Zameer, A.; Snyder, B.J.; Ge, C.; Lu, Q.R.; Rowitch, D.H.; Raine, C.S.; Brosnan, C.F.; et al. Notch1 signaling plays a role in regulating precursor differentiation during CNS remyelination. Proc. Natl. Acad. Sci. USA 2009, 106, 19162-19167. [CrossRef]

11. Jensen, S.K.; Yong, V.W. Activity-Dependent and Experience-Driven Myelination Provide New Directions for the Management of Multiple Sclerosis. Trends Neurosci. 2016, 39, 356-365. [CrossRef] [PubMed]

12. Huang, J.K.; Jarjour, A.A.; Nait Oumesmar, B.; Kerninon, C.; Williams, A.; Krezel, W.; Kagechika, H.; Bauer, J.; Zhao, C.; Baron-Van Evercooren, A.; et al. Retinoid X receptor gamma signaling accelerates CNS remyelination. Nat. Neurosci. 2011, 14, 45-53. [CrossRef] [PubMed]

13. Yuan, J.; Ge, H.; Liu, W.; Zhu, H.; Chen, Y.; Zhang, X.; Yang, Y.; Yin, Y.; Chen, W.; Wu, W.; et al. M2 microglia promotes neurogenesis and oligodendrogenesis from neural stem/progenitor cells via the PPARgamma signaling pathway. Oncotarget 2017, 8, 19855-19865. [CrossRef]

14. De La Fuente, A.G.; Lange, S.; Silva, M.E.; Gonzalez, G.A.; Tempfer, H.; van Wijngaarden, P.; Zhao, C.; Di Canio, L.; Trost, A.; Bieler, L.; et al. Pericytes Stimulate Oligodendrocyte Progenitor Cell Differentiation during CNS Remyelination. Cell Rep. 2017, 20, 1755-1764. [CrossRef] [PubMed]

15. Behrangi, N.; Namvar, N.; Ataei, M.; Dizaji, S.; Javdani, G.; Sanati, M.H. MMP9 Gene Expression Variation by Ingesting Tart Cherry and P-Coumaric Acid During Remyelination in the Cuprizone Mouse Model. Acta Med. Iran. 2017, 55, 539-549.

16. Kuboyama, K.; Tanga, N.; Suzuki, R.; Fujikawa, A.; Noda, M. Protamine neutralizes chondroitin sulfate proteoglycan-mediated inhibition of oligodendrocyte differentiation. PLoS ONE 2017, 12, e0189164. [CrossRef] [PubMed]

17. De Castro, F.; Ortega, M.C.; Bribián, A. Regulation of oligodendrocyte precursor migration during development, in adulthood and in pathology. Cell Mol. Life Sci. 2013, 70, 4355-4368. [CrossRef]

18. Clemente, D.; Ortega, M.C.; Arenzana, F.J.; de Castro, F. FGF-2 and anosmin-1 are selectively expressed in different types of multiple sclerosis lesions. J. Neurosci. 2011, 31, 14899-14909. [CrossRef]

19. Absinta, M.; Sati, P.; Reich, D.S. Advanced MRI and staging of multiple sclerosis lesions. Nat. Rev. Neurol. 2016, 12, 358-368. [CrossRef] [PubMed]

20. Franklin, R.J.M.; ffrench-Constant, C. Regenerating CNS myelin-From mechanisms to experimental medicines. Nat. Rev. Neurosci. 2017, 18, 753-769. [CrossRef]

21. Hein, K.; Gadjanski, I.; Kretzschmar, B.; Lange, K.; Diem, R.; Sa, M.B. Immunology and Microbiology An Optical Coherence Tomography Study on Degeneration of Retinal Nerve Fiber Layer in Rats with Autoimmune Optic Neuritis. Investig. Ophthalmol. Vis. Sci. 2012, 53, 157-163. [CrossRef]

22. Oertel, F.C.; Outteryck, O.; Knier, B.; Zimmermann, H.; Borisow, N.; Bellmann-strobl, J.; Blaschek, A.; Jarius, S.; Reindl, M.; Ruprecht, K.; et al. Optical coherence tomography in myelin- seropositive patients: A longitudinal study. J. Neuroiflamm. 2019, 5, $1-9$.

23. London, F.; Zéphir, H.; Drumez, E.; Labreuche, J.; Hadhoum, N.; Lannoy, J.; Hodel, J.; Vermersch, P.; Pruvo, J.-P.; Leclerc, X.; et al. Optical coherence tomography: A window to the optic nerve in clinically isolated syndrome. Brain 2019, 142, 903-915. [CrossRef]

24. Ratchford, J.N.; Quigg, M.E.; Conger, A.; Frohman, T.; Frohman, E.; Balcer, L.J.; Calabresi, P.A.; Kerr, D.A. Optical coherence tomography helps differentiate neuromyelitis optica and MS optic neuropathies. Neurology 2009, 73, 302-308. [CrossRef]

25. Tugcu, B.; Soysal, A.; Murat, K.; Yuksel, B.; Arpaci, B. Assessment of structural and functional visual outcomes in relapsing remittıng multıple sclerosis with visual evoked potentıals and optical coherence tomography. J. Neurol. Sci. 2013, 335, 182-185. [CrossRef] [PubMed]

26. Di Maggio, G.; Santangelo, R.; Guerrieri, S.; Bianco, M.; Ferrari, L.; Medaglini, S.; Rodegher, M.; Colombo, B.; Moiola, L.; Chieffo, R.; et al. Optical coherence tomography and visual evoked potentials: Which is more sensitive in multiple sclerosis? Mult. Scler. 2014, 20, 1342-1347. [CrossRef] [PubMed] 
27. Ashtari, F.; Emami, P.; Akbari, M. Association between retinal nerve fiber layer thickness and magnetic resonance imaging findings and intelligence in patients with multiple sclerosis. Adv. Biomed. Res. 2015, 4, 223.

28. Manogaran, P.; Hanson, J.V.M.; Olbert, E.D.; Egger, C.; Wicki, C.; Gerth-Kahlert, C.; Landau, K.; Schippling, S. Optical coherence tomography and magnetic resonance imaging in multiple sclerosis and neuromyelitis optica spectrum disorder. Int. J. Mol. Sci. 2016, 17, 1894. [CrossRef]

29. Puthenparampil, M.; Federle, L.; Poggiali, D.; Miante, S.; Signori, A.; Pilotto, E.; Rinaldi, F.; Perini, P.; Sormani, P.; Midena, E.; et al. Trans-synaptic degeneration in the optic pathway. A study in clinically isolated syndrome and early relapsing-remitting multiple sclerosis with or without optic neuritis. PLOS ONE 2017, 12, e0183957.

30. Talebi, M.; Nikanfar, M.; Sorkhabi, R.; Sharifipour, E.; Bahrebar, M.; Kiavar, A.; Andalib, S.; Khanli, H.M. Optic coherence tomography findings in relapsing-remitting multiple sclerosis patients of the northwest of Iran. Iran. J. Neurol. 2013, 12, 81-86.

31. Nolan-kenney, R.C.; Liu, M.; Akhand, O.; Calabresi, P.A.; Paul, F.; Petzold, A.; Balk, L.; Brandt, A.U.; Martínez-lapiscina, E.H.; Saidha, S.; et al. Optimal Intereye Difference Thresholds by Optical Coherence Tomography in Multiple Sclerosis: An International Study. Ann. Neurol. 2019, 85, 618-629. [CrossRef] [PubMed]

32. Gordon-Lipkin, E.; Calabresi, P.A. Optical coherence tomography: A quantitative tool to measure neurodegeneration and facilitate testing of novel treatments for tissue protection in multiple sclerosis. J. Neuroimmunol. 2017, 304, 93-96. [CrossRef]

33. Pulicken, M.; Gordon-Lipkin, E.; Balcer, L.J.; Frohman, E.; Cutter, G.; Calabresi, P.A. Optical coherence tomography and disease subtype in multiple sclerosis. Neurology 2007, 69, 2085-2092. [CrossRef] [PubMed]

34. Palomo, V.; Pérez, D.I.; Pérez, C.; Morales-García, J.A.; Soteras, I.; Alonso-Gil, S.; Encinas, A.; Castro, A.; Campillo, N.E.; Pérez-Castillo, A.; et al. 5-Imino-1,2,4-thiadiazoles: First small molecules As substrate competitive inhibitors of glycogen synthase kinase 3. J. Med. Chem. 2012, 55, 1645-1661. [CrossRef] [PubMed]

35. Medina-Rodriguez, E.M.; Bribián, A.; Boyd, A.; Palomo, V.; Pastor, J.; Lagares, A.; Gil, C.; Martínez, A.; Williams, A.; de Castro, F. Promoting in vivo remyelination with small molecules: A neuroreparative pharmacological treatment for Multiple Sclerosis. Sci. Rep. 2017, 7, 1-14.

36. Medina-Rodríguez, E.M.; Arenzana, F.J.; Pastor, J.; Redondo, M.; Palomo, V.; García De Sola, R.; Gil, C.; Martínez, A.; Bribián, A.; de Castro, F. Inhibition of endogenous phosphodiesterase 7 promotes oligodendrocyte precursor differentiation and survival. Cell. Mol. Life Sci. 2013, 70, 3449-3462. [CrossRef]

37. Sánchez-Cruz, A.; Villarejo-Zori, B.; Marchena, M.; Zaldivar-Díez, J.; Palomo, V.; Gil, C.; Lizasoain, I.; De La Villa, P.; Martínez, A.; De La Rosa, E.J.; et al. Modulation of GSK-3 provides cellular and functional neuroprotection in the rd10 mouse model of retinitis pigmentosa. Mol. Neurodegener. 2018, 13,1-10. [CrossRef]

38. Martín-Álvarez, R.; Paúl-Fernández, N.; Palomo, V.; Gil, C.; Martínez, A.; Mengod, G. A preliminary investigation of phoshodiesterase 7 inhibitor VP3.15 as therapeutic agent for the treatment of experimental autoimmune encephalomyelitis mice. J. Chem. Neuroanat. 2017, 80, 27-36. [CrossRef] [PubMed]

39. Ellsworth, S.G.; Yalamanchali, A.; Zhang, H.; Grossman, S.A.; Hobbs, R.; Jin, J.-Y. Comprehensive Analysis of the Kinetics of Radiation-Induced Lymphocyte Loss in Patients Treated with External Beam Radiation Therapy. Radiat. Res. 2020, $193,73-81$. [CrossRef]

40. Petzold, A.; Balcer, L.J.; Calabresi, P.A.; Costello, F.; Frohman, T.C.; Frohman, E.M.; Martinez-lapiscina, E.H.; Green, A.J. Retinal layer segmentation in multiple sclerosis: A systematic review and meta-analysis. Lancet Neurol. 2017, 16, 797-812. [CrossRef]

41. Mecha, M.; Carrillo-Salinas, F.J.; Feliú, A.; Mestre, L.; Guaza, C. Microglia activation states and cannabinoid system: Therapeutic implications. Pharmacol. Ther. 2016, 166, 40-55. [CrossRef]

42. Mecha, M.; Feliú, A.; Machín, I.; Cordero, C.; Carrillo-Salinas, F.; Mestre, L.; Hernández-Torres, G.; Ortega-Gutiérrez, S.; López-Rodríguez, M.; de Castro, F.; et al. 2-AG limits Theiler's virus induced acute neuroinflammation by modulating microglia and promoting MDSCs. Glia 2018, 66, 1447-1463. [CrossRef]

43. Silbermann, E.; Wooliscroft, L.; Bourdette, D. Using the Anterior Visual System to Assess Neuroprotection and Remyelination in Multiple Sclerosis Trials. Curr. Neurol. Neurosci. Rep. 2017, 18, 1-9. [CrossRef]

44. Martinez-Lapiscina, E.H.; Arnow, S.; Wilson, J.A.; Saidha, S.; Preiningerova, J.L.; Oberwahrenbrock, T.; Brandt, A.U.; Pablo, L.E.; Guerrieri, S.; Gonzalez, I.; et al. Retinal thickness measured with optical coherence tomography and risk of disability worsening in multiple sclerosis: A cohort study. Lancet Neurol. 2016, 15, 574-584. [CrossRef]

45. Villoslada, P.; Cuneo, A.; Gelfand, J.; Hauser, S.L.; Green, A. Color vision is strongly associated with retinal thinning in multiple sclerosis. Mult. Scler. 2012, 18, 991-999. [CrossRef]

46. Green, A.J.; McQuaid, S.; Hauser, S.L.; Allen, I.V.; Lyness, R. Ocular pathology in multiple sclerosis: Retinal atrophy and inflammation irrespective of disease duration. Brain 2010, 133, 1591-1601. [CrossRef] [PubMed]

47. Matthews, P.M.; Datta, G. Positron-emission tomography molecular imaging of glia and myelin in drug discovery for multiple sclerosis. Expert Opin. Drug Discov. 2015, 10, 557-570. [CrossRef] [PubMed]

48. Bove, R.M.; Green, A.J. Remyelinating Pharmacotherapies in Multiple Sclerosis. Neurotherapeutics 2017, 14, 894-904. [CrossRef]

49. Leferink, P.S.; Heine, V.M. The Healthy and Diseased Microenvironments Regulate Oligodendrocyte Properties Implications for Regenerative Medicine. Am. J. Pathol. 2018, 188, 39-52. [CrossRef] [PubMed]

50. Falcão, A.M.; Van Bruggen, D.; Marques, S.; Meijer, M.; Jäkel, S.; Agirre, E.; Floriddia, E.M.; Vanichkina, D.P.; Williams, A.; Guerreiro-Cacais, A.O.; et al. Disease-specific oligodendrocyte lineage cells arise in multiple sclerosis. Nat. Med. 2018, 24, 1837-1844. [CrossRef] 
51. Zeis, T.; Howell, O.W.; Reynolds, R.; Schaeren-wiemers, N. Molecular pathology of Multiple Sclerosis lesions reveals a heterogeneous expression pattern of genes involved in oligodendrogliogenesis IdL. Exp. Neurol. 2018, 305, 76-88. [CrossRef]

52. Jäkel, S.; Agirre, E.; Falcão, A.M.; Bruggen, D.; Lee, K.W.; Knuesel, I.; Malhotra, D.; Williams, A.; Castelo-branco, G. Altered human oligodendrocyte heterogeneity in multiple sclerosis. Nature 2019, 566, 543-547. [CrossRef]

53. Yeung, M.S.Y.; Djelloul, M.; Steiner, E.; Bernard, S.; Possnert, G.; Brundin, L.; Frisén, J. Europe PMC Funders Group Oligodendrocyte generation dynamics in multiple sclerosis. Nature 2019, 566, 538-542. [CrossRef] [PubMed]

54. Tremblay, M.Ě.; Lowery, R.L.; Majewska, A.K. Microglial interactions with synapses are modulated by visual experience. PLoS Biol. 2010, 8, e1000527. [CrossRef] [PubMed]

55. Zabala, A.; Vazquez-villoldo, N.; Rissiek, B.; Gejo, J.; Martin, A.; Palomino, A.; Perez-samartín, A.; Pulagam, K.R.; Lukowiak, M.; Capetillo-zarate, E.; et al. P 2 X 4 receptor controls microglia activation and favors remyelination in autoimmune encephalitis. EMBO Mol. Med. 2018, 10, 1-20. [CrossRef]

56. Butovsky, O.; Ziv, Y.; Schwartz, A.; Landa, G.; Talpalar, A.E.; Pluchino, S.; Martino, G.; Schwartz, M. Microglia activated by IL-4 or IFN- $\gamma$ differentially induce neurogenesis and oligodendrogenesis from adult stem/progenitor cells. Mol. Cell. Neurosci. 2006, 31, 149-160. [CrossRef]

57. Lloyd, A.F.; Davies, C.L.; Miron, V.E. ScienceDirect Microglia: Origins, homeostasis, and roles in myelin repair. Curr. Opin. Neurobiol. 2017, 47, 113-120. [CrossRef]

58. Plemel, J.R.; Stratton, J.A.; Michaels, N.J.; Rawji, K.S.; Zhang, E.; Sinha, S.; Baaklini, C.S.; Dong, Y.; Ho, M.; Thorburn, K.; et al. Microglia response following acute demyelination is heterogeneous and limits infiltrating macrophage dispersion. Sci. Adv. 2020, 6,1-15. [CrossRef]

59. Kalincik, T.; Manouchehrinia, A.; Sobisek, L.; Jokubaitis, V.; Spelman, T.; Horakova, D.; Havrdova, E.; Trojano, M.; Izquierdo, G.; Lugaresi, A.; et al. Towards personalized therapy for multiple sclerosis: Prediction of individual treatment response. Brain 2017, 140, 2426-2443. [CrossRef]

60. Plemel, J.R.; Liu, W.; Yong, V.W. Remyelination therapies: A new direction and challenge in multiple sclerosis. Brain 2017, 140, 2426-2443. [CrossRef] [PubMed]

61. Schepers, M.; Tiane, A.; Paes, D.; Sanchez, S.; Rombaut, B.; Vanmierlo, T. Targeting Phosphodiesterases-Towards a Tailor-Made Approach in Multiple Sclerosis Treatment. Front. Immunol. 2019, 10, 1-17. [CrossRef] [PubMed]

62. Beurel, E.; Kaidanovich-Beilin, O.; Yeh, W.-I.; Song, L.; Palomo, V.; Michalek, S.M.; Woodgett, J.R.; Harrington, L.E.; EldarFinkelman, H.; Martinez, A.; et al. Regulation of Th1 Cells and Experimental Autoimmune Encephalomyelitis by Glycogen Synthase Kinase-3. J. Immunol. 2013, 190, 5000-5011. [CrossRef] [PubMed]

63. Barkhof, F. The optic nerve should be included as one of the typical CNS regions for establishing dissemination in space when diagnosing MS-Commentary. Mult. Scler. 2018, 24, 125-126. [CrossRef] [PubMed]

64. Tintoré, M.; Montalban, X. The optic nerve should be included as one of the typical CNS regions for establishing dissemination in space when diagnosing MS-No. Mult. Scler. 2018, 24, 123-125. [CrossRef]

65. Filippi, M.; Preziosa, P.; Meani, A.; Ciccarelli, O.; Mesaros, S.; Rovira, A.; Frederiksen, J.; Enzinger, C.; Barkhof, F.; Gasperini, C.; et al. Prediction of a multiple sclerosis diagnosis in patients with clinically isolated syndrome using the 2016 MAGNIMS and 2010 McDonald criteria: A retrospective study. Lancet. Neurol. 2018, 17, 133-142. [CrossRef]

66. Aktas, O.; Hartung, H.-P. CSI: Multiple sclerosis. Tracing optic nerve involvement by standardized optical coherence tomography. Ann. Neurol. 2019, 85, 615-617. [CrossRef]

67. Davion, J.-B.; Lopes, R.; Drumez, É.; Labreuche, J.; Hadhoum, N.; Lannoy, J.; Vermersch, P.; Pruvo, J.-P.; Leclerc, X.; Zéphir, H.; et al. Asymptomatic optic nerve lesions. Neurology 2020, 94, 2468-2478. [CrossRef]

68. Heidari, M.; Radcliff, A.B.; Mclellan, G.J.; Ver, J.N.; Chan, K.; Kiland, J.A. Evoked potentials as a biomarker of remyelination. Proc. Nat. Acad. Sci. USA 2019, 116, 27074-27083. [CrossRef]

69. Moliné-Velázquez, V.; Cuervo, H.; Vila del Sol, V.; Ortega, M.C.; Clemente, D.; de Castro, F. Myeloid-Derived Suppressor Cells Limit the Inflammation by Promoting T Lymphocyte Apoptosis in the Spinal Cord of a Murine Model of Multiple Sclerosis. Brain Pathol. 2011, 21, 678-691. [CrossRef]

70. Moliné-Velázquez, V.; Ortega, M.C.; Vila, V.; Melero-Jerez, C.; de Castro, F.; Clemente, D. Neurobiology of Disease The synthetic retinoid Am80 delays recovery in a model of multiple sclerosis by modulating myeloid-derived suppressor cell fate and viability. Neurobiol. Dis. 2014, 67, 149-164. [CrossRef]

71. Marín-Bañasco, C.; Benabdellah, K.; Melero-Jerez, C.; Oliver, B.; Pinto-Medel, M.J.; Hurtado-Guerrero, I.; de Castro, F.; Clemente, D.; Fernández, O.; Martín, F.; et al. Gene therapy with mesenchymal stem cells expressing IFN- $B$ ameliorates neuroinflammation in experimental models of multiple sclerosis. Br. J. Pharmacol. 2017, 174, 238-253. [CrossRef] [PubMed]

72. Melero-jerez, C.; Alonso-Gómez, A.; Moñivas, E.; Lebrón-Galán, R.; Machín-Díaz, I.; De Castro, F.; Clemente, D. Neurobiology of Disease The proportion of myeloid-derived suppressor cells in the spleen is related to the severity of the clinical course and tissue damage extent in a murine model of multiple sclerosis. Neurobiol. Dis. 2020, 140, 104869. [CrossRef]

73. Torres-Platas, G.S.; Comeau, S.; Rachalski, A.; Bo, D.G.; Cruceanu, C.; Turecki, G.; Giros, B.; Mechawar, N. Morphometric characterization of microglial phenotypes in human cerebral cortex. J. Neuroinflamm. 2014, 11, 12. [CrossRef] [PubMed]

74. Lee, S.W.; Gajavelli, S.; Spurlock, M.S.; Andreoni, C.; De Rivero Vaccari, J.P.; Bullock, M.R.; Keane, R.W.; Dietrich, W.D. Microglial Inflammasome Activation in Penetrating Ballistic-Like Brain Injury. J. Neurotrauma 2018, 35, 1681-1693. [CrossRef] [PubMed] 
75. Parra, I.; Martínez, I.; Ramírez-García, G.; Tizabi, Y.; Mendieta, L. Differential Effects of LPS and 6-OHDA on Microglia's Morphology in Rats: Implications for Inflammatory Model of Parkinson's Disease. Neurotox. Res. 2020, 37, 1-11. [CrossRef] [PubMed]

76. Leavitt, V.M.; Brandstadter, R.; Fabian, M.; Katz Sand, I.; Klineova, S.; Krieger, S.; Lewis, C.; Lublin, F.; Miller, A.; Pelle, G.; et al. Dissociable cognitive patterns related to depression and anxiety in multiple sclerosis. Mult. Scler. 2020, 26, 1247-1255. [CrossRef] 